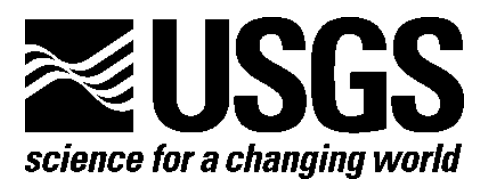

\title{
National Land Imaging Requirements (NLIR) Pilot Project Summary Report-Summary of Moderate Resolution Imaging User Requirements
}

By Carolyn Vadnais and Greg Stensaas

Open-File Report 2014-1107

U.S. Department of the Interior

U.S. Geological Survey 


\section{U.S. Department of the Interior \\ SALLY JEWELL, Secretary}

\section{U.S. Geological Survey \\ Suzette M. Kimball, Acting Director}

U.S. Geological Survey, Reston, Virginia: 2014

For more information on the USGS-the Federal source for science about the Earth, its natural and living resources, natural hazards, and the environment-visit http://www.usgs.gov or call 1-888-ASK-USGS

For an overview of USGS information products, including maps, imagery, and publications, visit $h$ ttp://www.usgs.gov/pubprod

To order this and other USGS information products, visit http://store.usgs.gov

Any use of trade, firm, or product names is for descriptive purposes only and does not imply endorsement by the U.S. Government.

Although this information product, for the most part, is in the public domain, it also may contain copyrighted materials as noted in the text. Permission to reproduce copyrighted items must be secured from the copyright owner.

Suggested citation:

Vadnais, Carolyn, and Stensaas, Greg, 2014, National Land Imaging Requirements (NLIR) Pilot Project Summary Report-Summary of Moderate Resolution Imaging User Requirements: U.S. Geological Survey Open-File Report 2014-1107, 46 p., http://dx.doi.org/10.3133/ofr20141107.

ISSN 2331-1258 (online) 


\section{Contents}

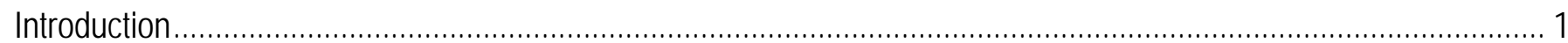

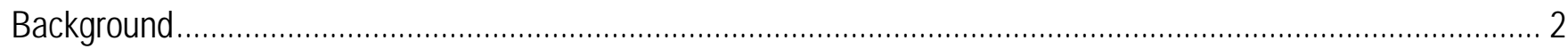

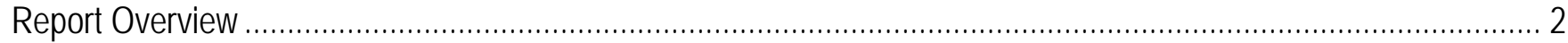

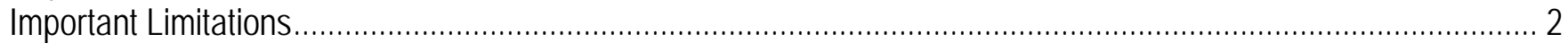

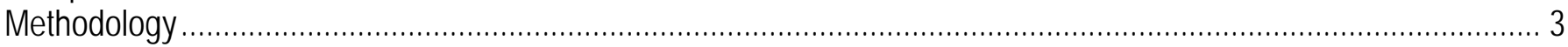

Scope

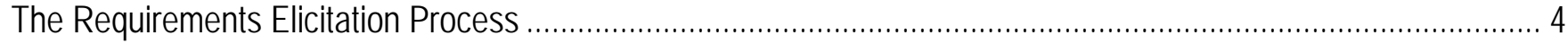

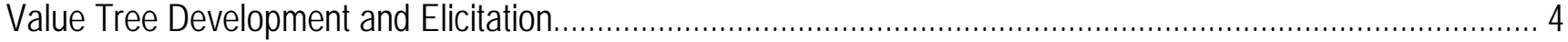

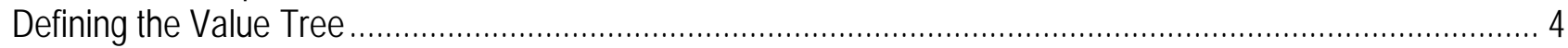

Determining Earth Observation Dataset Inputs and Their Impact............................................................ 5

Identification of Unmet Needs....................................................................................................

Verification of Value Tree Information.............................................................................................

User Requirements Development and Elicitation ....................................................................................

Use of Value Tree Information to Prepare Preliminary Requirements ....................................................... 9

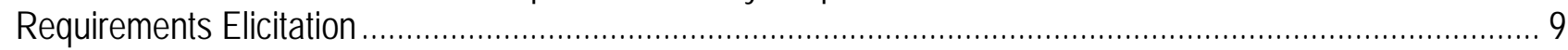

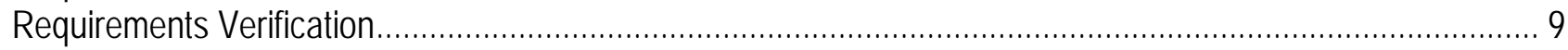

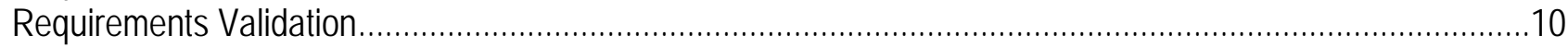

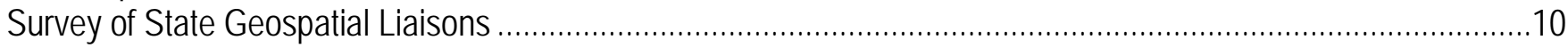

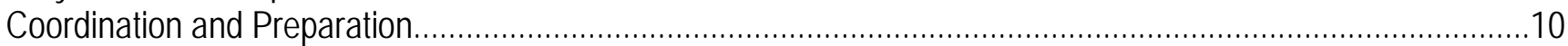

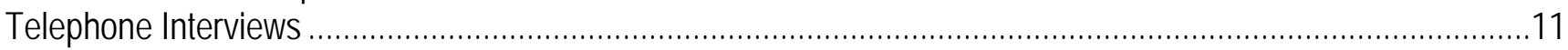

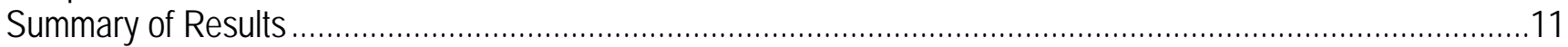

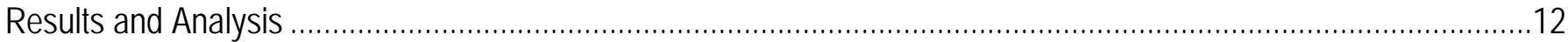

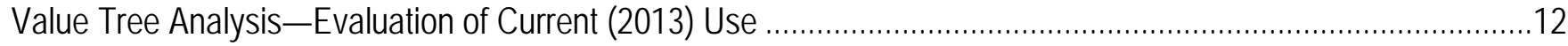

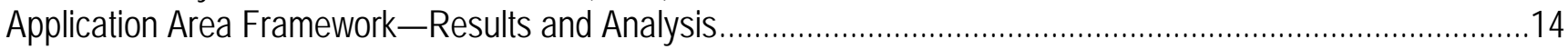

Societal Benefit Area Framework—Results and Analysis .....................................................................17



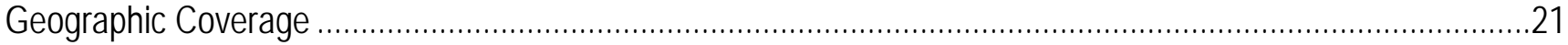

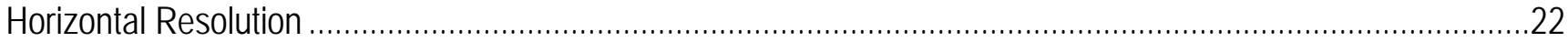

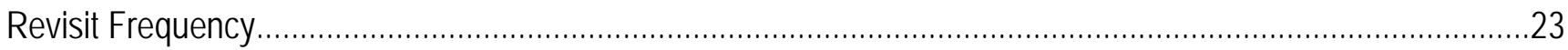

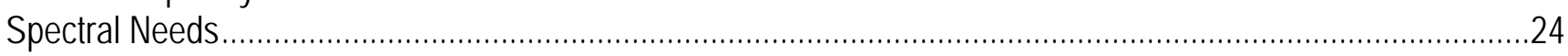

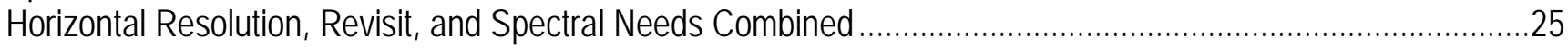

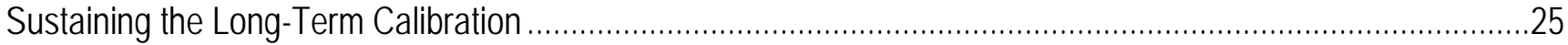

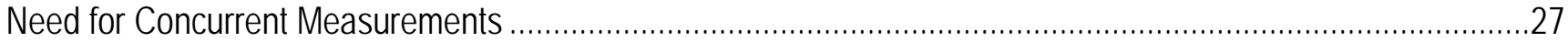

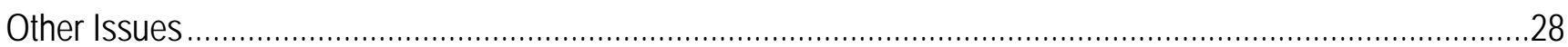

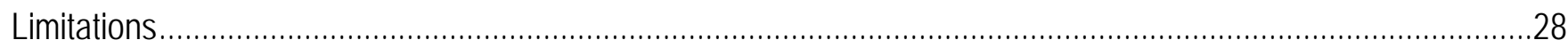

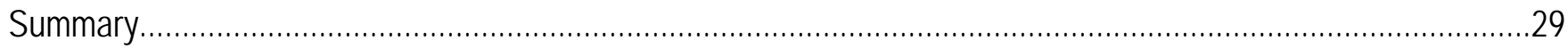

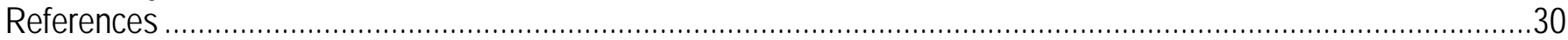

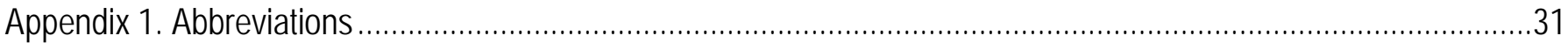

Appendix 2. Survey of State Geospatial Liaisons ..................................................................................

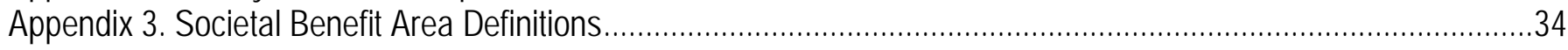

Appendix 4. Preliminary User Requirements Summary Information ......................................................................35 


\section{Figures}

Figure 1. Generic value tree for the U.S. Department of the Interior, showing the various levels connecting

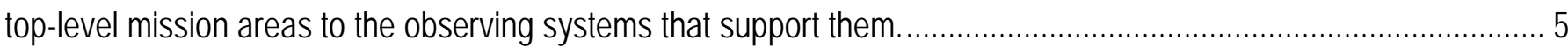

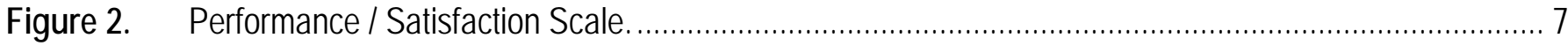

Figure 3. Summary of applications identified by the State Geospatial Liaisons supported by moderate

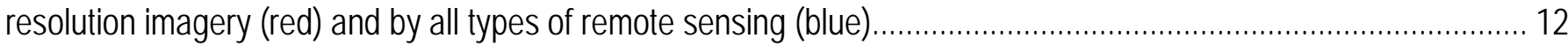

Figure 4. The relative impact of moderate resolution data on each of the application areas.............................. 14

Figure 5. Cumulative impact of each of the spectral bands from moderate resolution sources across the application areas. From this graphic, one can get a sense of which bands overall have the greatest impact and which bands have the least impact

Figure 6. Impact of each of the spectral bands from moderate resolution sources within each application area. This presentation of the data provides a picture of which application areas are the heaviest users of moderate resolution imagery, and how similar or unique the individual application areas are in their use of the various bands

Figure 7. Impact of each of the spectral bands from moderate resolution sources across all of the application areas. From this graphic, one can to see that the NIR band has the greatest impact and the PAN band has the least impact

Figure 8. The relative impact of moderate resolution data on each of the Societal Benefit Areas.

Figure 9. Cumulative impact of each of the spectral bands from moderate resolution sources across the societal benefit areas.

Figure 10. Impact of each of the spectral bands from moderate resolution sources within each SBA. This presentation of the data provides a picture of which SBAs are the heaviest users of moderate resolution imagery, and how similar or unique the individual SBAs are in their use of the various bands. 
Figure 11. Extending data from a previous Portfolio Analysis Machine ${ }^{\mathrm{TM}}$ analysis, this figure shows the cumulative impact of each of the spectral bands from moderate resolution sources across the societal benefit areas. 20

Figure 12. Impact of each of the spectral bands from moderate resolution sources across all of the societal benefit areas. From this graphic, one can see that the near infrared band has the most impact and the panchromatic band

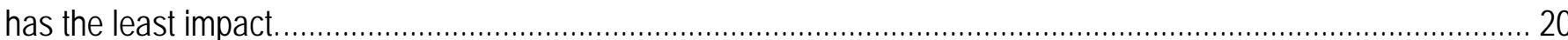

Figure 13. National Land Imaging Requirements pilot project user requirements summary by requirement type... 21 Figure 14. Percentage of threshold requirements in each of the four geographic coverage categories indicated... 22 Figure 15. Percentage of threshold requirements in each of the seven horizontal resolution categories indicated. Fifty-seven percent of the threshold requirements can be met by data that are 30 meters or less in resolution 23

Figure 16. Revisit frequency for the 114 threshold requirements identified in the pilot project.............................. 24 


\section{Tables}

Table 1. Member Bureaus of the Department of the Interior Remote Sensing Working Group (DOIRSWG)........ 3

Table 2. Global Change Master Directory variables used to document requirements identified in the pilot project and the number of total requirements (threshold, breakthrough, and target) documented against each 8

Table 3. National Land Imaging Requirements pilot project application areas, key products or services, and the

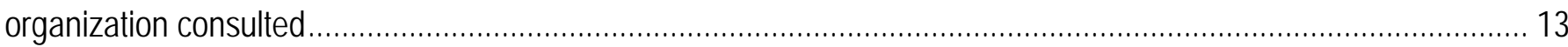

Table 4. Comparison of threshold requirements met by 30-meter resolution and 8-day revisit and those requirements no longer met if revisit drops to 16 days. 26

Table 5. Comparison of threshold requirements met by 15-meter resolution and any combination of visible and near infrared (VNIR) and shortwave infrared (SWIR) data, and those no longer met if SWIR is not available 


\title{
National Land Imaging Requirements (NLIR) Pilot Project Summary Report-Summary of Moderate Resolution Imaging User Requirements Manuscript
}

\author{
By Carolyn Vadnais ${ }^{1}$ and Greg Stensaas ${ }^{2}$
}

\section{Introduction}

As part of the National Land Imaging Requirements (NLIR) Project, the U.S. Geological Survey (USGS) will develop and operate a functional capability to obtain, characterize, manage, maintain and prioritize all Earth observation (EO) land remote sensing user requirements. The goal is a better understanding of community needs that can be supported with land remote sensing resources, and a means to match needs with appropriate solutions in an effective and efficient way. The NLIR Project will enable program managers to systematically manage, assess, and exploit EO user requirements to support data-driven decisions to better serve the user community.

The NLIR Project comprises two components. The first component is focused on the development of a system to capture, store, and analyze user requirements. The system, called the Earth Observation Requirements Evaluation System (EORES), is being developed jointly with the National Oceanic and Atmospheric Administration (NOAA) through a process that will incrementally deliver the full capability in the next 12-18 months. The second component is the mechanism and processes to elicit and document user requirements that will populate EORES.

To develop the second component, the user requirements elicitation methodology was exercised and refined through a pilot project that ran from June through September 2013. The pilot project served as a risk reduction activity for the NLIR Project and builds on the best elements of several welldocumented methodologies and previous work by NOAA and the U.S. Group on Earth Observations (USGEO) as described in the National Strategy for Civil Earth Observations (Office of Science and Technology Policy, 2013). This pilot project focused specifically on requirements for moderate resolution imagery [5-120-meter (m) resolution]; however, the overall NLIR Project elicitation will follow a solution-agnostic approach and address all land EO user requirements to establish a baseline expected to endure for multiple years.

The purpose of this summary report is to provide a high-level overview of the requirements elicitation process that was exercised through the pilot project and provide an early analysis of the sample of moderate resolution imaging user requirements developed to date to support ongoing USGS sustainable land imaging study needs. The elicitation process documented in this report and lessons learned in the pilot project will be used to enhance and fully document the NLIR elicitation process.

The pilot project engaged a limited set of Federal Government users from the operational and research communities, and therefore, the information collected represents only a subset of all land imaging user requirements. However, based on a comparison of results, trends, and analysis, the pilot

\footnotetext{
${ }^{1}$ Integrity Applications Incorporated.

2 US Geological Survey (USGS).
} 
project results depicted a strong baseline of typical applications areas and user needs for moderate resolution imagery.

Because these results are preliminary and represent only a sample of users and application areas, the information from this report should only be used to indicate general user needs for the applications covered. Users of the information are cautioned that use of specific numeric results may be inappropriate without additional research. Any information used or cited from this report should specifically be cited as preliminary findings.

\section{Background}

Through the NLIR Project within the Land Remote Sensing Program, the USGS is developing a functional capability to obtain, characterize, manage, maintain, and prioritize land remote sensing requirements with the goal of better understanding the community needs that can be supported by land remote sensing resources and to match needs with appropriate solutions in an effective and efficient way. This capability will help guide program development and direction and support program and budget justifications. The current (2013) NLIR Project comprises two primary components: (1) development of a requirements and capabilities information repository and the analytical tools to compare requirements and capabilities; and (2) the pilot project that is the subject of this summary report.

\section{Report Overview}

The "Methodology" section describes, at a high level, the methodology used to generate the representative sample of user requirements and the "Results and Analysis" section describes the preliminary results and accompanying analysis. The final section draws conclusions from the results and the analysis to date and identifies the next steps in the process. Appendix 1 contains a list of abbreviations used in the report.

\section{Important Limitations}

The overarching purpose of the pilot project was to develop an effective, transparent, and repeatable process to capture land imaging user requirements. As would be expected in a pilot effort, a starting methodology was developed, then tested, then modified, and tested again, and the project team will continue to make additional refinements in the process before the final documentation is delivered. Because of the pilot project focus on moderate resolution applications and requirements only, and because of the limited time available, the team was not able to exercise all elements of the process, specifically some later elements of the process that would follow extensive work with Subject Matter Experts (SMEs) to refine and solidify the full set of user requirements, such as prioritizing requirements and assigning relative weights. Additional work will be completed between the end of pilot project data collection (September 2013) and the closeout of the project in January 2014 to ensure that a comprehensive process is developed and delivered.

Similarly, the pilot project did not elicit requirements from the full spectrum of users and potential users, nor did the pilot project formally validate the requirements developed. Because the set of user requirements described and analyzed in this report is the result of an evolving process and selective elicitations, it should not be considered a comprehensive or definitive statement of moderate resolution imaging requirements. 


\section{Methodology}

The pilot project served as a risk reduction activity for the overall NLIR Project by developing and exercising processes for the elicitation and documentation of user requirements in a platform agnostic format that ensures requirements are captured, evaluated, and prioritized in a traceable, transparent and repeatable manner. Focusing the pilot project on moderate resolution imaging bounded the project scope and led to the generation of a set of preliminary user requirements that may be informative for the USGS in the near term. This report conveys a description and analysis of these moderate resolution imaging requirements while the project team finalizes and documents the requirements elicitation process.

The pilot project used a two-part strategy to meet its objectives: (1) the main effort developed and used a formal requirements elicitation process; and (2) a secondary effort completed an informal survey of state geospatial liaisons. The remainder of the Methodology section provides an overview of these two activities.

\section{Scope}

The pilot project focused on applications for moderate resolution imagery within the U.S. Department of Agriculture (USDA) and the Department of the Interior (DOI), and considerable effort was expended to try to ensure a wide sample of application areas across the two Departments.

Within USDA, the team engaged the USDA Remote Sensing Advisor and the U.S. Forest Service Remote Sensing Program Manager to identify the appropriate initial contacts within each of the subordinate Agencies and Services.

Within DOI, the approach was two-fold. First, the team contacted the DOI Remote Sensing Working Group member for each of the Bureaus (see table 1) to explain the project and seek their advice about potential application areas and SMEs. Second, the team contacted or met with nearly all of the 31 USGS Program Coordinators to gain an understanding of their activities and identify appropriate SMEs.

Table 1. Member Bureaus of the Department of the Interior Remote Sensing Working Group (DOIRSWG).

\section{Department of the Interior Remote Sensing Working Group (DOIRSWG)}

Member Bureaus
Bureau of Indian Affairs
Bureau of Land Management
Bureau of Ocean Energy Management
Bureau of Reclamation
U.S. Fish and Wildlife Service
National Park Service
Office of Surface Mining
U.S. Geological Survey

An important element of the pilot project was to engage practitioners within each application area rather than managers or headquarters personnel. Ideally the team was looking for individuals who work with moderate resolution data and develop or deliver the key products or services as part of their day-to-day job. These individuals are closest to the applications and generally have a clear 
understanding of the value and any shortcomings associated with current (2013) data sources as it applies to their activity, as well as unmet needs at the user level.

\section{The Requirements Elicitation Process}

The elicitation process comprised two phases, both involving extensive contact with SMEs across the range of application areas examined. The first phase was the development of value trees to understand the current (2013) use and relative criticality of moderate resolution imagery to the application. The second phase was the capture of user requirements.

The following sections describe value tree development and data collection, followed by a description of requirements development and elicitation.

\section{Value Tree Development and Elicitation}

This step in the formal process includes three parts: (1) defining the structure and components of the value tree; (2) using expert elicitation to value the set of inputs to key products or services; and (3) identifying unmet needs.

Defining the Value Tree

The development of requirements begins with establishing the strategic context for the requirements. To establish this context, the project team reviewed the USDA and DOI strategic plans and the relevant strategic planning of subordinate organizations and activities. The team then developed value trees to identify the connections to departmental strategic goals and to collect information on current (2013) applications, the overall performance of those applications, and the performance of the inputs that go into them.

A value tree is a hierarchical framework in which top-level objectives may have other objectives or desired attributes within them, which may, in turn, have other lower-level attributes, and so on. A generic, single branch of the value tree using the DOI Strategic Plan to define the top of the tree is shown in figure 1 . The DOI Strategic Plan identifies mission areas that have goals and specific strategies associated with the goals, forming the top part of the value tree. The project team, working in collaboration with SMEs from the bureaus and agencies, defined mission service areas that encompass similar activities aimed at achieving the strategy with which they are aligned. Then the elicitation team and the SMEs identified key products or services that represent the most important capabilities associated with each mission service area. Each of the key products or services are generated using some or all of a combination of direct observations from Earth observing systems (such as Landsat), other products or services, or models, collectively referred to as Earth observation datasets (EO datasets).

During the development of the value trees, when a branch with no connection to moderate resolution imaging was identified, the project team halted further development of that branch and focused on the branches with moderate resolution imaging application. 


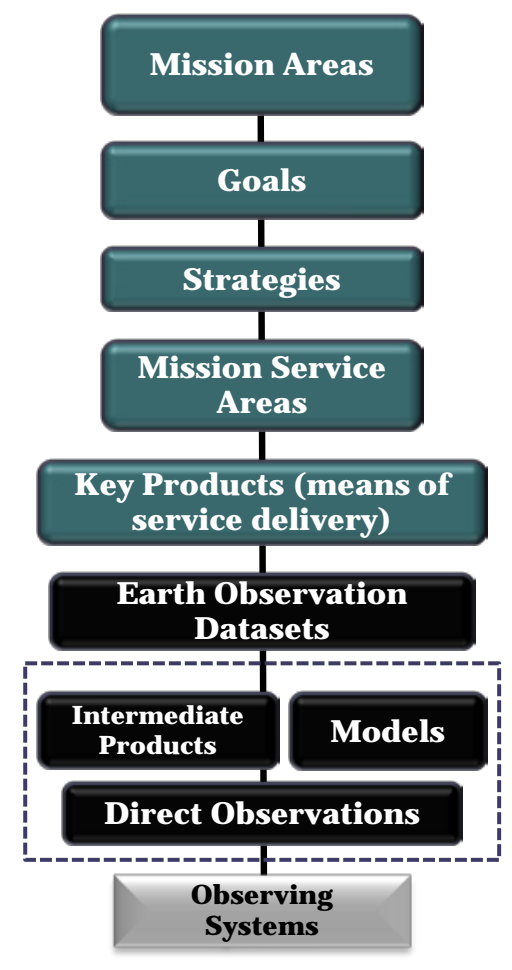

Figure 1. Generic value tree for the U.S. Department of the Interior, showing the various levels connecting toplevel mission areas to the observing systems that support them.

The top of the value tree may be defined in a number of ways depending on the intended application. For the pilot project, the team developed the value trees using an organizational construct that connects the delivery of value to top-level, organizational strategic goals and objectives. This may be contrasted with, and is compatible with the value tree construct based on Societal Benefit Areas such as those developed by the international Group on Earth Observations and USGEO. In this construct, the delivery of value is connected to a societal benefit rather than an organizational strategic goal. One advantage of the value tree development used in the pilot project is the ability to reorganize the key products or services under a different construct for the upper part of the value tree, minimizing additional work needed to support multiple applications.

After defining the structure of the value tree from the key products or services upward, the next step is to identify the EO dataset inputs into each key product or service and to determine the relative impact of each input on the production of the key product or service.

\section{Determining Earth Observation Dataset Inputs and Their Impact}

The project team used a combination of information from previous studies (Office of Science and Technology Policy, 2013, p 15-17; Miller and others, 2013) and review of agency plans, reports, and web sites, refined by extensive collaboration with SMEs, to determine the set of inputs into each key product or service. The team then entered the key products or services and their sets of inputs into a spreadsheet to be evaluated during the value tree elicitation sessions with the SMEs. Although the focus of the pilot project is on moderate resolution imaging requirements, all of the various inputs were identified and scored to provide a relative comparison for the moderate resolution imaging component. 
As the elicitations continued, the team used higher levels of grouping of inputs to accelerate the value tree data collection. These variations were managed within the Portfolio Analysis Machine (PALMA ${ }^{\mathrm{TM}}$ ) model to ensure consistent analysis of the integrated results.

The Portfolio Analysis Machine (PALMA ${ }^{\mathrm{TM}}$ ) is a computer program developed by the MITRE Corporation (Schmidt, 2011) that enables the user to apply multi-attribute utility theory to the analysis of portfolios of systems as they relate to high-level goals. The PALMA ${ }^{\mathrm{TM}}$ software visually depicts the overall value tree, quantifies the qualitative information collected in the expert elicitation, and enables analysis of complex, multidimensional problems. The project team modeled the value trees in PALMA $^{\mathrm{TM}}$ using the tree structure and scores elicited from the SMEs, then integrated the individual results into the larger, overall value tree for each Department.

The spreadsheet is structured to facilitate an orderly evaluation of each key product or service and its inputs using the swing weighting technique that was used in the development of the National Strategy for Civil Earth Observations (Office of Science and Technology Policy, 2013, p 15-17; Miller and others, 2013), and in similar ongoing work by NOAA (V. Ries and M. Yapur, National Oceanic and Atmospheric Administration (NOAA), oral communication, 2013). To standardize and calibrate the evaluation across the suite of different key products or services, the performance/satisfaction scale shown in Figure 2 was used throughout the elicitations.

Swing weighting is a proven technique to evaluate the relative criticality among many inputs when objective techniques are impractical or impossible (Kirkwood, 1997; Parnell and others, 2011, p. 334-337; Meyer and Booker, 2001, p. 3; Environmental Protection Agency, 2011, p. 1). It is a structured method of expert elicitation to define the impact of a particular capability (system, product, or service) on a key product or service. Subject matter experts assign an overall performance score (on a standardized scale, see Figure 2) to the key product or service when all of the input capabilities are in use. The SMEs then score the overall performance when a particular capability is removed as an input but all others remain, indicating the "swing" from best case to worst case associated with that particular capability. When multiple SMEs are involved, they arrived at an agreed to score through discussion. The difference in the score with and without the input is the criticality of the input. All of the inputs feeding into a key product or service are scored in this way and the results are combined using the PALMA ${ }^{\mathrm{TM}}$ model, enabling the comparison of the relative impact of each individual input on the key product or service or on any node in the value tree.

Identification of Unmet Needs

One of the last steps in the value tree elicitation sessions was to identify and discuss any unmet needs that had not already been uncovered during the elicitation. Unmet needs did not always surface during value tree development and evaluation because the value tree reflects only satisfaction with current (2013) data sources to meet needs, but does not necessarily reflect needs for which current (2013) data sources are completely inadequate or nonexistent. Capturing these provided valuable inputs into the requirements development process. The project team subsequently referred to unmet needs to formulate draft user requirements for use in the requirements elicitation process. 


\begin{tabular}{|c|c|l|}
\hline \multicolumn{3}{|c|}{ Performance / Satisfaction Scale } \\
\hline 100 & Ideal & Meets all requirements and exceeds some \\
\hline 90 & Fully Satisfied & Meets all requirements \\
\hline 80 & Good & Meets all major requirements with minor limitations \\
\hline 70 & & \\
\hline 60 & Fair & Meets most major requirements, with significant limitations \\
\hline $\mathbf{5 0}$ & & \\
\hline 40 & Poor & Fails to meet many major requirements, but provides some value \\
\hline 30 & & \\
\hline 20 & Very Poor & Fails to meet most major requirements, but provides minor value \\
\hline 10 & & \\
\hline 1 & No Capability & Provides no value \\
\hline
\end{tabular}

Figure 2. Performance / Satisfaction Scale.

Verification of Value Tree Information

The last step in the value tree elicitation process is the verification of the information collected and the results of the impact analysis from PALMA ${ }^{\mathrm{TM}}$. Although the project team typically immediately resolved questions identified during PALMA ${ }^{\mathrm{TM}}$ model building, this step affords the SMEs and the project team an opportunity to mutually resolve any remaining questions. For the pilot project, this step was executed with only a small number of the SMEs early on simply to demonstrate the step. This step will be substantially more important in the longer-term NLIR Project when full sets of requirements will be developed and users will also be asked to establish priorities among their needs.

\section{User Requirements Development and Elicitation}

The development of the value tree and the collection of information on the relative criticality of the various inputs to a key product or service provide a snapshot in time of the current (2013) capability placed in the context of high-level organizational strategy and goals. The activity to this point mirrors similar ongoing work by NOAA (Ries, V., and Yapur, M., National Oceanic and Atmospheric Administration, oral commun., 2013) and in the National Strategy for Civil Earth Observations (Office of Science and Technology Policy, 2013) [evaluated by the Societal Benefit Area (SBA) instead of organization], while offering some refinements. The subsequent challenge is to pivot to a requirements perspective that is system and solution agnostic and that focuses on the "what" rather than the "how"the needs and not the solutions.

The field of requirements engineering acknowledges many types of requirements including functional and nonfunctional requirements, system, subsystem, and component requirements, design requirements, interface requirements, and so on (Young, 2004). The focus of the pilot project, and of the NLIR Project as a whole, is to document user requirements for land imaging and, specifically for this report, moderate resolution land imaging. User requirements are the specification of the characteristics of Earth observation data or measurements by a user for a particular application.

The pilot project defined three types of user requirements: (1) threshold; (2) breakthrough; and (3) target, as defined below.

Threshold Requirement - The minimum requirement to be met to ensure that an Earth observation (EO) dataset or service is useful. Below this minimum, the benefit derived does not compensate for the additional cost involved in using the dataset or service. 
$\square$ Breakthrough Requirement-An intermediate requirement level between threshold and target which, if achieved, would result in a substantial improvement for the targeted application. The breakthrough level may be considered to be optimum from a cost-benefit point of view when planning, designing, or creating an EO dataset or service.

$\square$ Target Requirement—-The value above which further improvement of the EO dataset or service would provide only limited improvement in performance for the application in question. The cost of improving the dataset or service beyond the target requirement would not be matched by a corresponding benefit.

The information acquired for the NLIR Project will use a well-defined standardized taxonomy adopted from the National Aeronautics and Space Administration (NASA) Global Change Master Directory (GCMD) that provides a topic/term/variable framework for defining observable parameters (Olsen and others, 2013). Requirements related to 35 unique GCMD variables were captured in the pilot project (table 2).

Table 2. Global Change Master Directory variables used to document requirements identified in the pilot project and the number of total requirements (threshold, breakthrough, and target) documented against each.

\begin{tabular}{|c|c|c|c|}
\hline Global Change Master Directory Variables & $\begin{array}{c}\text { Number of } \\
\text { Requirements }\end{array}$ & Global Change Master Directory Variables & $\begin{array}{c}\text { Number of } \\
\text { Requirements }\end{array}$ \\
\hline Albedo & 3 & Soil classification & 2 \\
\hline Biomass & 2 & Soil disturbance & 2 \\
\hline Burn severity & 4 & Soil moisture / water content & 5 \\
\hline Cloud presence & 2 & Sulfur dioxide & 4 \\
\hline Dust / ash / smoke & 4 & Surface reflectance & 5 \\
\hline Eruption dynamics / lahars and debris flow & 1 & Surface water extent & 13 \\
\hline Eruption dynamics / pyroclastic flow & 2 & Top of atmosphere reflectance & 2 \\
\hline Eruption dynamics / lava speed / flow & 2 & Tree cover canopy & 1 \\
\hline Land cover & 3 & Vegetation condition & 34 \\
\hline Land surface elements & 10 & Vegetation cover & 6 \\
\hline Land surface temperature & 11 & Vegetation disturbance & 6 \\
\hline Land use classes & 13 & Vegetation species & 25 \\
\hline Lava flow temperature & 2 & Vegetation type & 1 \\
\hline Leaf Area Index (LAI) & 2 & Volcanic activity & 2 \\
\hline Mineral type & 10 & Volcanic deposits & 3 \\
\hline Nonphotosynthetic vegetation & 5 & Wetland classification & 1 \\
\hline Salinity & 1 & Wildfires & 1 \\
\hline
\end{tabular}

To the degree possible, the team attempted to consistently assign GCMD variables to needs for similar information, while at the same time trying to take out ties to particular observing technologies. For instance, applications that rely upon some type of vegetative index more fundamentally need information about vegetation condition. Vegetation condition can be assessed using multispectral band differencing, but also can be obtained in other ways, so that the requirement can be more broadly written as a need for vegetation condition, not specific to the Normalized Difference Vegetation Index (NDVI) or some other vegetative index.

Within the Earth observation community, requirements typically are described using an environmental observing attribute such as spatial resolution, sampling frequency, area of coverage, or accuracy. In the pilot project, the primary attributes elicited were geographic coverage, horizontal 
resolution, frequency of observation or revisit time, length of data record (importance of continuity/calibration), and data latency. The team also explored accuracy as an attribute with SMEs during elicitations; however, SMEs generally were not able to specify accuracy attributes in a tangible way. The team will explore and develop additional techniques for eliciting accuracy information and other attributes for the NLIR elicitation documentation and associated effort.

Although it was difficult to remain system agnostic in elicitation discussions exploring needs for particular spectral bands, the project team gathered needs in this area as well.

The following sections describe the use of value tree information to prepare preliminary requirements, the elicitation process, and verification and validation of the requirements.

Use of Value Tree Information to Prepare Preliminary Requirements

The data collected in value tree elicitation supports the preparation of a preliminary set of threshold requirements in several ways. First, the value tree identifies where moderate resolution imaging plays a role and the relative criticality of that role. Second, the data highlight areas of weak performance or lower overall satisfaction and the value tree can indicate where improvement would produce the largest overall improvement in performance. Third, the unmet needs identified by the SMEs in the value tree elicitation often point to potential moderate resolution imaging requirements.

By organizing the requirements within the same value tree construct, the requirements are traceable through mission service areas upward to departmental strategic goals, thus establishing the validity of the requirements for the organization.

Using the information from the value tree elicitation and analysis of the PALMA ${ }^{\mathrm{TM}}$ model output, the project team developed a preliminary set of threshold requirements and entered them in a requirements collection worksheet for use in the elicitation session with the SMEs. Where information on unmet needs pointed to them, the team developed possible breakthrough and target requirements and entered them in the worksheet as well.

Requirements Elicitation

After preparing a set of preliminary requirements, the project team met again with the SMEs to review the draft list, fill in missing information, and better understand the requirements. To date, this is generally as far as the team was able to proceed with the SMEs in the pilot project-essentially a first review of the draft requirements.

Going forward the team will need to further develop the details of each requirement, particularly for each of the primary attributes. To do this the project team intends to rely on a more free-form variation of a standard knowledge and requirements elicitation technique known as laddering (Corbridge and others, 1994; Chen and others, 2002). The laddering technique does not rely on a survey or questionnaire with a set of questions but rather follows the threads generated by answers to questions of the type "how can you tell that..." and "explain what you mean by..." and asks similar explanatory questions until each thread has been unpacked to a clearly understood level.

The project team documented the results of the preliminary discussions in an extensive spreadsheet that has been distilled to the shorter form accompanying this report. In many cases, the narrative explanation of needs requires further analysis to translate into specific numeric values for requirements attributes.

Requirements Verification

Verification of requirements is the determination that the recorded requirements have been documented accurately — the "requirements are right." This step typically involves a review by the 
SMEs to ensure the requirements analysts have captured the stated requirement accurately. The representative sample of moderate resolution imaging requirements at the center of this report were only verified by their respective SMEs in a very preliminary sense. Additional verification steps will be required once the requirements are more fully developed.

Requirements Validation

Validation of requirements is the determination, often through a high-level formal review and approval process, that the stated requirements are correct and complete-the "right requirements." Because of the limited time available in the pilot project, and the fact that the requirements captured still require further development to be fully verified, formal validation was not possible. In addition, the approach to be used for validation has not yet been determined and will be the subject of discussion with the wider NLIR Project team before process implementation.

\section{Survey of State Geospatial Liaisons}

In addition to the requirements elicitation process described above, the pilot project completed an informal survey of liaisons in the USGS Geospatial Liaison Network. The liaisons are Federal employees housed in National Spatial Data Infrastructure (NSDI) Partnership Offices across the Nation. The liaisons represent and coordinate National Geospatial Program (NGP) initiatives in state, local, and other Federal agencies, cultivate and maintain long-term relationships, and develop partnerships and supporting agreements. Among other duties, the relevant functions of the liaisons include the following:

Advise and consult on geospatial data and technology.

Coordinate through and support the statewide coordinating councils that include representation and participation from all sectors within the state.

Coordinate with state and local governments.

Provide a leadership role in coordinating with Federal agencies in states or regions.

Seek opportunities to create relationships and collaborate with tribes.

Seek partnerships with not-for-profit organizations, the private sector, universities, and consortia.

Advise and consult with USGS disciplines to maximize their participation in NGP programs and the NSDI.

Support emergency operations/homeland security activities.

Serve on-site at specific Federal agencies to ensure strong USGS science and emergency operations linkages.

The USGS Geospatial Liaison Network is the "local face" of the USGS NSDI and NGP programs and, for the pilot project, provided insight into the various applications of land remote sensing in general and moderate resolution imagery in particular across the states. The pilot project sought to obtain a general sense of the uses of moderate resolution imagery among the supported state, local, and tribal governments, academia, and the private sector and to assess the need for and potential value in more detailed, formal elicitations of these groups.

\section{Coordination and Preparation}

To maximize the information collected while minimizing the effect on liaison workload, the project team contacted the NGP Partner and User Engagement Liaison Coordinator to coordinate the 
best approach to the interviews and to review the proposed questions and information to be provided to the liaisons in advance of the telephone discussions. Taking advantage of a regularly scheduled liaison coordination teleconference, the project team provided an overview of the project and answered questions about the information to be gathered and the application of the information. The team subsequently contacted a select number of liaisons to review and refine the questions and prepared a brief set of Frequently Asked Questions. The Partner and User Engagement Liaison Coordinator then sent the information to all of the liaisons to begin the interview process.

The list of questions used in the interviews is shown in Appendix 2. Survey of State Geospatial Liaisons.

\section{Telephone Interviews}

Once the liaisons had received the project information and interview questions, the project team completed telephone interviews with them. The team interviewed 31 of the 34 liaisons with most interviews lasting 30 to 40 minutes and some interviews lasting as long as 2 hours.

Generally two members of the project team participated in the interview with each liaison and gathered notes on the answers to the questions and any other related discussion. The notes have been collected and analyzed to summarize the results. The results of this informal survey provide supplemental information for the more formal elicitation process and the relevant results are highlighted in the analysis below.

\section{Summary of Results}

The liaisons identified 10 primary application areas supported by remote sensing within their states as well as the subset of applications that relied on moderate resolution imagery (see fig. 3). A more detailed review of the initial results of the liaison interview analysis will be provided within the final NLIR Project deliverables. This effort was preliminary in preparation for NLIR and was used to obtain enhanced understanding from USGS partners on potential land imagery use. 


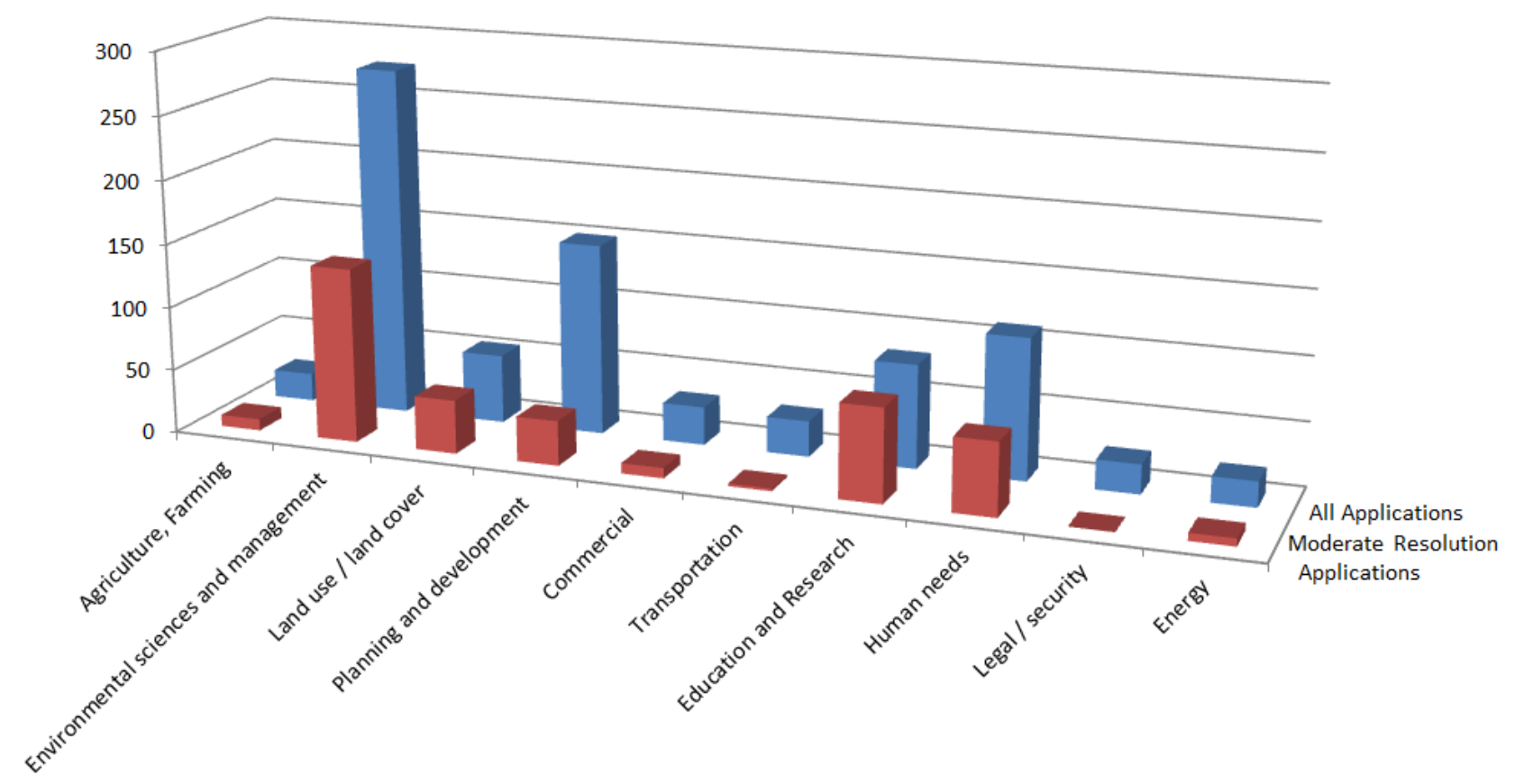

Figure 3. Summary of applications identified by the State Geospatial Liaisons supported by moderate resolution imagery (red) and by all types of remote sensing (blue).

\section{Results and Analysis}

The results for the pilot project are presented in two parts. The "Value Tree AnalysisEvaluation of Current (2013) Use" section contains the results of the value tree analysis, which reflects an evaluation of subject matter expert inputs regarding the relative criticality and performance of current (2013) sources of moderate resolution imagery. The results have been documented in two ways to illustrate the flexibility of the process to support analysis in different frameworks. The team chose to align each of the key products or services to user-specific application areas as well as to SBA constructs. Both results are presented.

The second part of the results section, "User Requirements—A Preliminary Set”, contains summary information about the requirements elicited and documented in the pilot project.

\section{Value Tree Analysis-Evaluation of Current (2013) Use}

The project team organized the set of key products or services into application areas to facilitate analysis (table 3). The alignment of key products or services to application areas, along with the primary corresponding organization from which subject matter expert(s) were engaged also is shown.

The assignment of key products or services to application areas was somewhat subjective and, in many cases, a particular product could have been assigned to any of several application areas. In these cases of multiple possible application areas, the team used their best judgment to assign a reasonable placement. 
Table 3. National Land Imaging Requirements pilot project application areas, key products or services, and the organization consulted.

\begin{tabular}{|c|c|c|}
\hline Application Area & Key Products & Subject Matter Expert Organization \\
\hline \multirow{11}{*}{ Agriculture } & Actuarial rate maps & \multirow{3}{*}{ Risk Management Agency ${ }^{1}$} \\
\hline & Compliance monitoring investigations & \\
\hline & Pasture rangeland insurance & \\
\hline & Global crop area estimation & \multirow{3}{*}{ Foreign Agricultural Service ${ }^{1}$} \\
\hline & Global crop yield estimation & \\
\hline & Rapid response to global agricultural crises & \\
\hline & NASS area sampling frame & National A oricultural Statistics Service ${ }^{1}$ \\
\hline & National crop forecasting & National Agricultural Statistics Service ${ }^{\star}$ \\
\hline & Crop residue monitoring & Agricultural Research Service ${ }^{1}$ \\
\hline & National agriculture disaster response & Natural Resources Conservation Service ${ }^{1}$ \\
\hline & Yield and water use estimates & Agricultural Research Service ${ }^{1}$ \\
\hline \multirow{7}{*}{ Climate and Land Use } & Global Land Cover 30-meter Dataset & \multirow{7}{*}{ U.S. Geological Survey ${ }^{2}$} \\
\hline & Irrigation monitoring and research & \\
\hline & National drought assessment & \\
\hline & National irrigated lands dynamics & \\
\hline & National Phenology Assessment (NPA) & \\
\hline & National land cover change assessment & \\
\hline & Vegetation Change Tracker (VCT) & \\
\hline \multirow{11}{*}{ Forestry } & $\begin{array}{l}\text { Burned Area Emergency Response (BAER) Burned Area Reflectance } \\
\text { Classification (BARC) }\end{array}$ & \multirow{11}{*}{ U.S. Forest Service ${ }^{1}$} \\
\hline & \begin{tabular}{|l|} 
Rapid Assessment of Vegetation Condition (RAVG) \\
\end{tabular} & \\
\hline & Monitoring Trends in Burn Severity (MTBS) & \\
\hline & Effectiveness of mitigation actions & \\
\hline & Forest disturbance assessment & \\
\hline & Forest disturbance queuing & \\
\hline & Forest resource mapping for inventory and monitoring & \\
\hline & National insect and disease risk map & \\
\hline & Digital soil mapping & \\
\hline & Multiresolution Land Characteristics (MRLC) tree canopy cover & \\
\hline & Regional scale forest mapping & \\
\hline \multirow{5}{*}{ Land Management } & Detailed vegetation classification & \multirow{5}{*}{ Bureau of Land Management ${ }^{2}$} \\
\hline & Emergency stabilization and rehabilitation plans & \\
\hline & Local drought assessments & \\
\hline & Multi-district mapping & \\
\hline & Sage Grouse conservation & \\
\hline \multirow{3}{*}{ Mineral Resources } & Environmental impact assessments & \multirow{3}{*}{ U.S. Geological Survey ${ }^{2}$} \\
\hline & Mineral deposit modeling & \\
\hline & Minerals assessment & \\
\hline \multirow{4}{*}{ Natural Resource Conservation } & Conservation plan maps & \multirow{4}{*}{ Natural Resources Conservation Service ${ }^{1}$} \\
\hline & Soil survey interpretation maps & \\
\hline & Wildlife and landscape initiatives & \\
\hline & Resource inventories & \\
\hline \multirow{4}{*}{ Solid Earth Hazards } & Hazards communication & \multirow{4}{*}{ U.S. Geological Survey ${ }^{2}$} \\
\hline & Volcano assessment & \\
\hline & Volcano monitoring & \\
\hline & Volcano research & \\
\hline \multirow{2}{*}{ Surface Mining } & Contemporaneous reclamation monitoring & \multirow{2}{*}{ Office of Surface Mining ${ }^{2}$} \\
\hline & Monitoring long-term restoration of mined areas & \\
\hline \multirow{3}{*}{ Water Management } & Consumptive water use & Bureau of Reclamation $^{2}$ \\
\hline & National watershed modeling & U.S. Geological Survey ${ }^{2}$ \\
\hline & Riparian vegetation mapping & Bureau of Reclamation $^{2}$ \\
\hline \multirow{3}{*}{ Wildlife/Ecosystems } & Ecosystem carbon assessment & 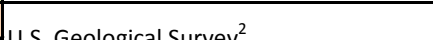 \\
\hline & Global ecosystem mapping & U.S. Geological Survey \\
\hline & Migratory bird surveys and management plans & U.S. Fish and Wildlife Service ${ }^{2}$ \\
\hline & LANDFIRE existing vegetation products & U.S. Geological Survey ${ }^{2}$ \\
\hline Intermediate Products & National Cropland Data Layer (NCDL) & National Agricultural Statistics Service ${ }^{1}$ \\
\hline & National Land Cover Dataset (NLCD) & U.S. Geological Survey ${ }^{2}$ \\
\hline
\end{tabular}

${ }^{1}$ U.S. Department of Agriculture ${ }^{2}$ U.S. Department of the Interior 


\section{Application Area Framework—Results and Analysis}

The following figures demonstrate some of the possible ways in which results from this type of analysis might be presented. For this analysis all application areas were assumed to be equally weighted. "Impact," as used within the PALMA ${ }^{\mathrm{TM}}$ model, is a measure of the relative criticality of a given data source as evaluated in the application area at a given node in the value tree if that data were removed as an input source. The "impact" to an application area is the summation of all of the incremental impacts of removing those individual inputs at all relevant nodes of the value tree. The impact is a relative number, not equivalent to a percentage, but useful as a means of comparison to the relative impact of other elements.

A summary of the relative impact of moderate resolution data (aggregate impacts from all sources) on each of the application areas is shown in figure 4. Note that all of the application areas are affected to some extent because the pilot project intentionally elicited data from activities that use moderate resolution data.

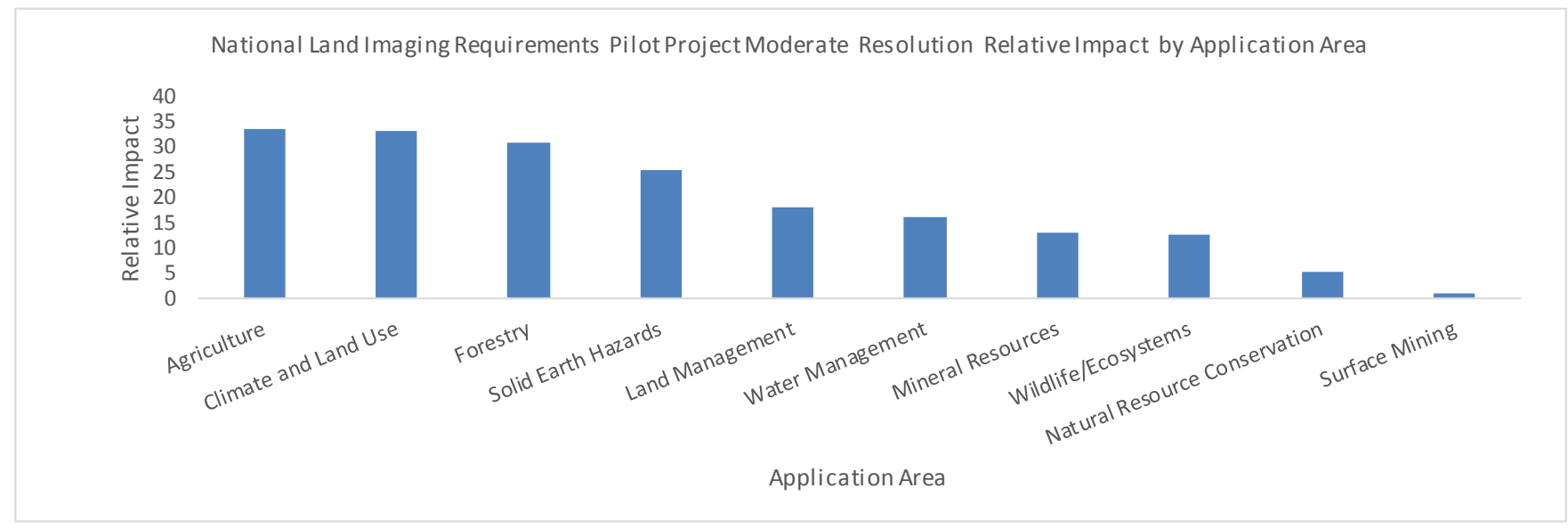

Figure 4. The relative impact of moderate resolution data on each of the application areas.

The relative impact of each spectral band on each application area can be conveyed in two different ways. The overall impact of each spectral band across all application areas is shown in figure 5 , with the relative contributions of each area reflected in the colored segments of each bar. Conversely, Figure 6 shows the relative impact of each spectral band within each application area.

The impact of each spectral band from moderate resolution sources across all of the application areas is summarized in figure 7. 


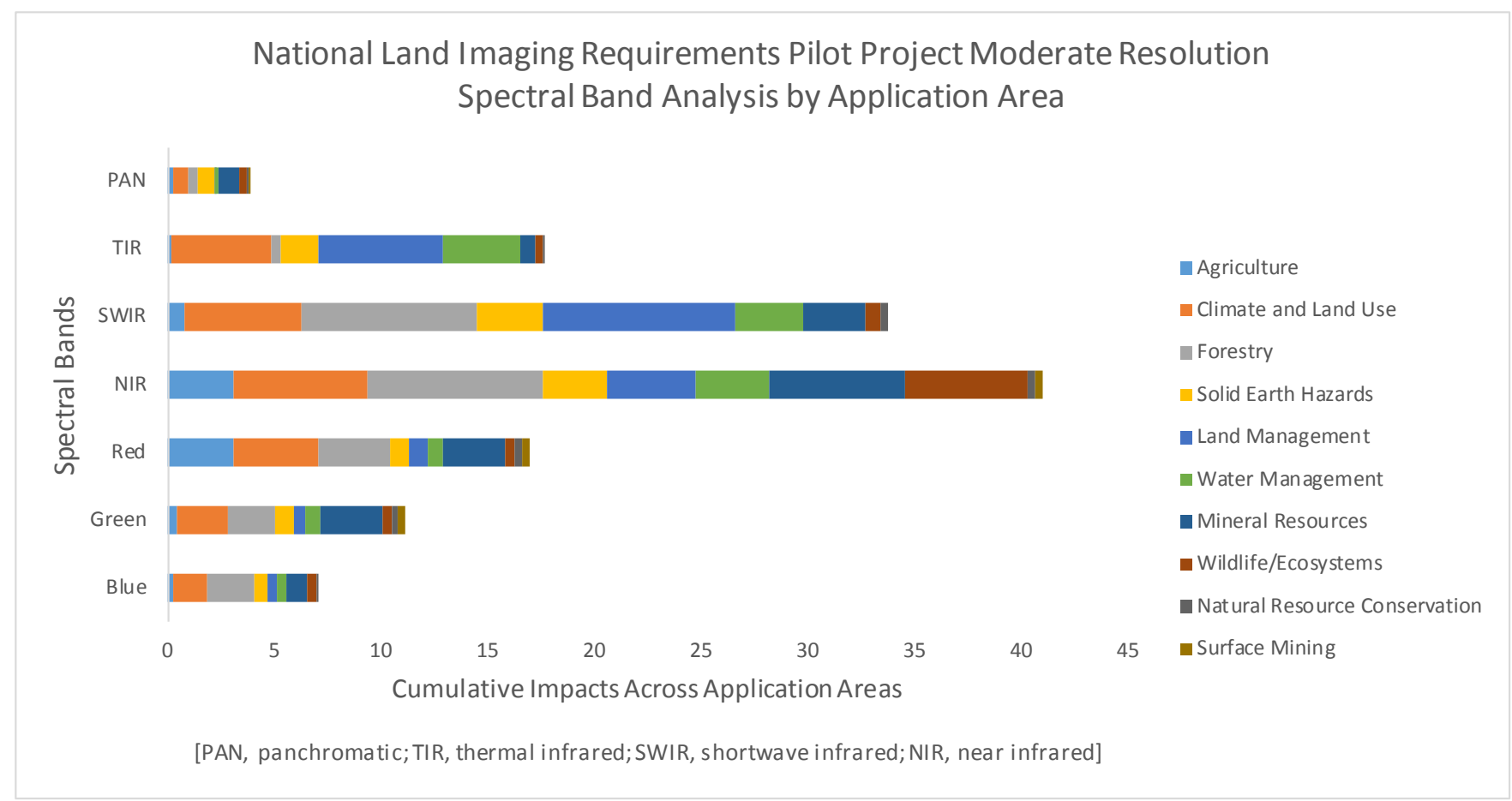

Figure 5. Cumulative impact of each of the spectral bands from moderate resolution sources across the application areas. From this graphic, one can get a sense of which bands overall have the greatest impact and which bands have the least impact. 


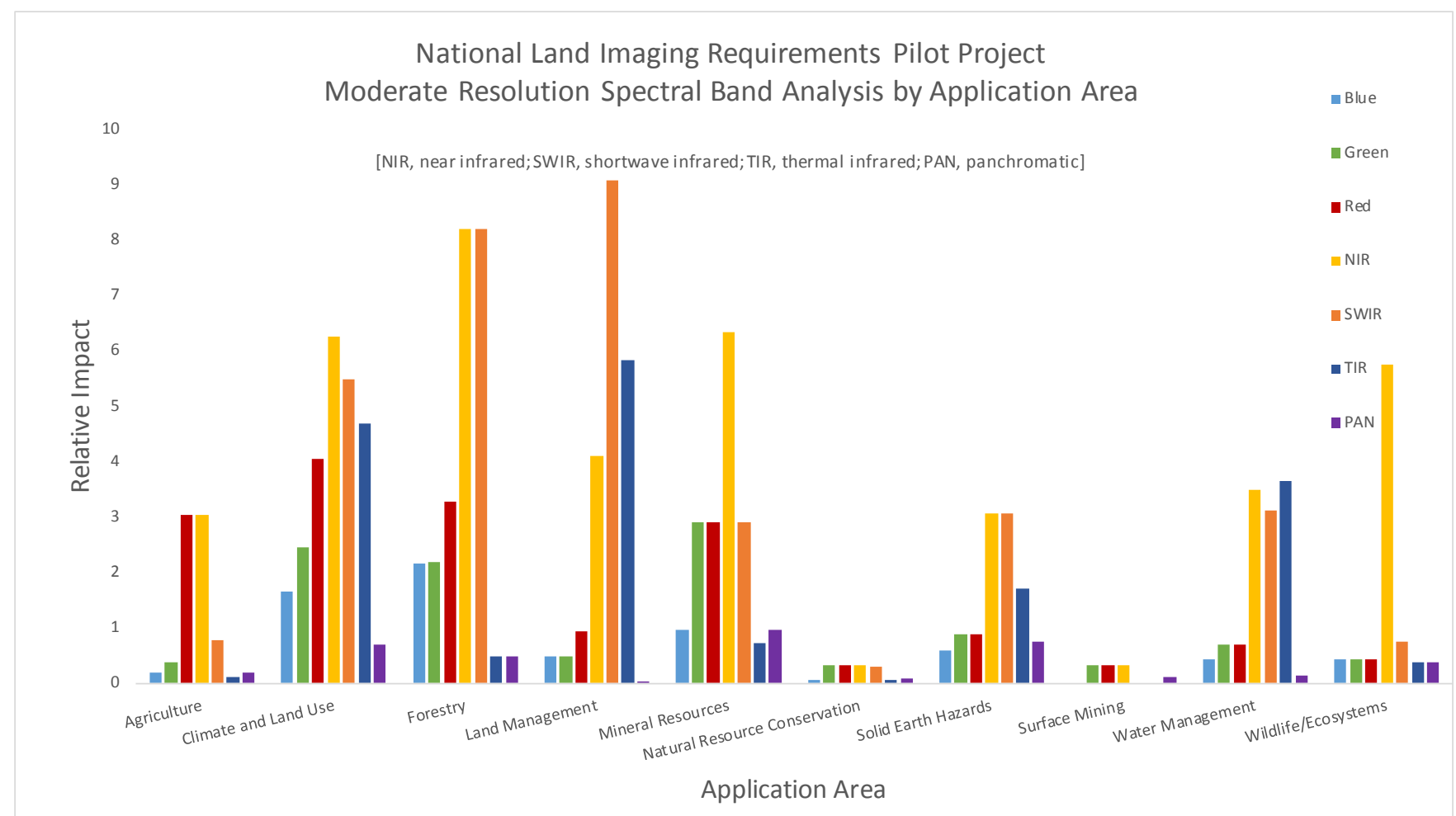

Figure 6. Impact of each of the spectral bands from moderate resolution sources within each application area. This presentation of the data provides a picture of which application areas are the heaviest users of moderate resolution imagery, and how similar or unique the individual application areas are in their use of the various bands. 


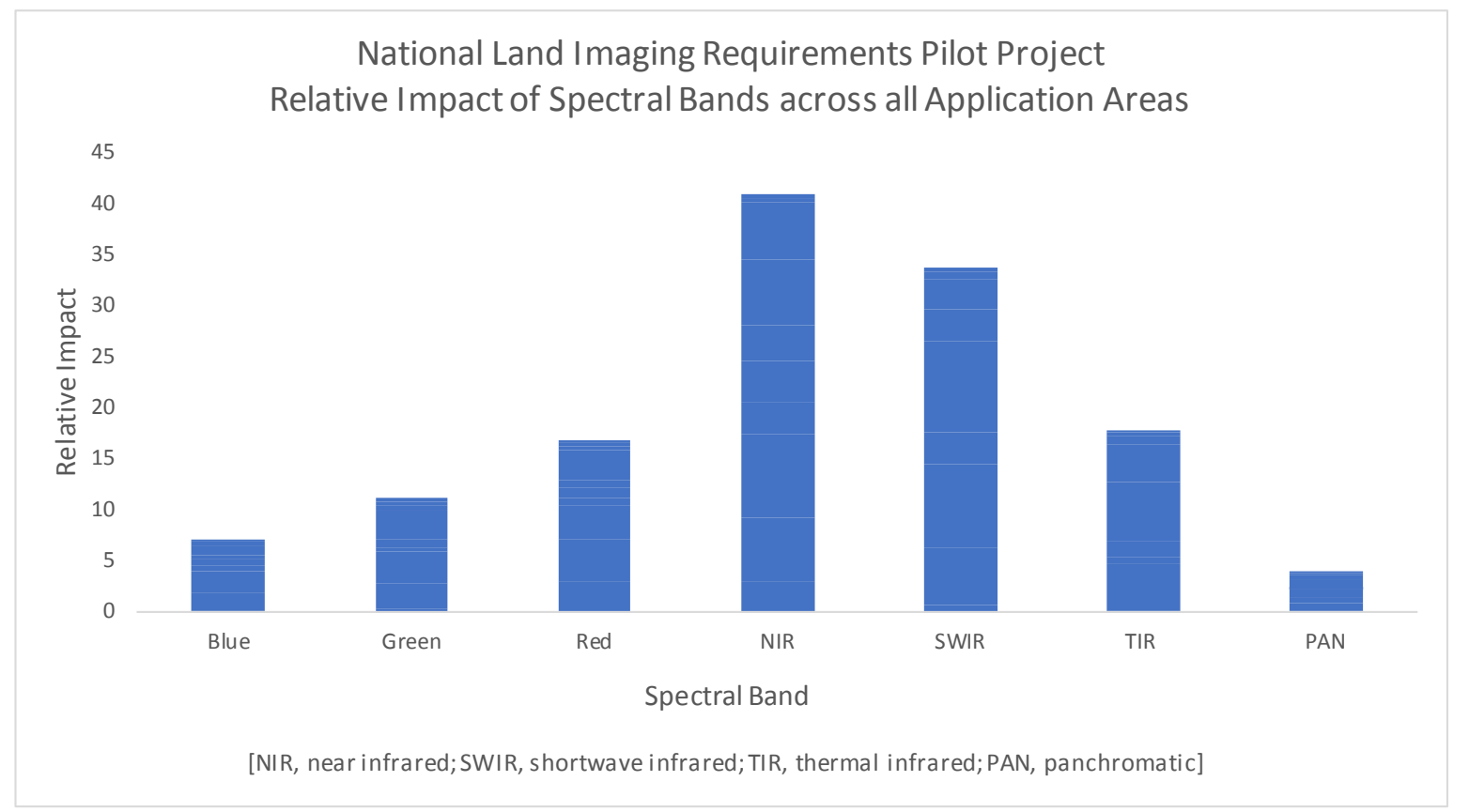

Figure 7. Impact of each of the spectral bands from moderate resolution sources across all of the application areas. From this graphic, one can to see that the NIR band has the greatest impact and the PAN band has the least impact.

Societal Benefit Area Framework-Results and Analysis

To generate the same analysis from a SBA perspective, the project team assigned each of the key products or services to the six relevant SBAs. The team used the SBA definitions established in the National Strategy for Civil Earth Observations. The definitions are in Appendix 3. Societal Benefit Area Definitions. The SBAs determined to be relevant for the pilot project were agriculture and forestry, climate, disasters, ecosystems, energy and mineral resources, and water resources.

The assignment of key products or services to SBAs was somewhat subjective and in some cases an individual key product or service could reasonably be assigned to more than one SBA. In those cases, the team applied its analytical expertise. Additionally, because the analysis also is based on a limited sample of data, the results should only be used as illustrative of what the impacts look like within an SBA framework, not a definitive analysis.

A summary of the relative impact of moderate resolution data (aggregate impacts from all sources) on each of the SBAs is shown in figure 8. 


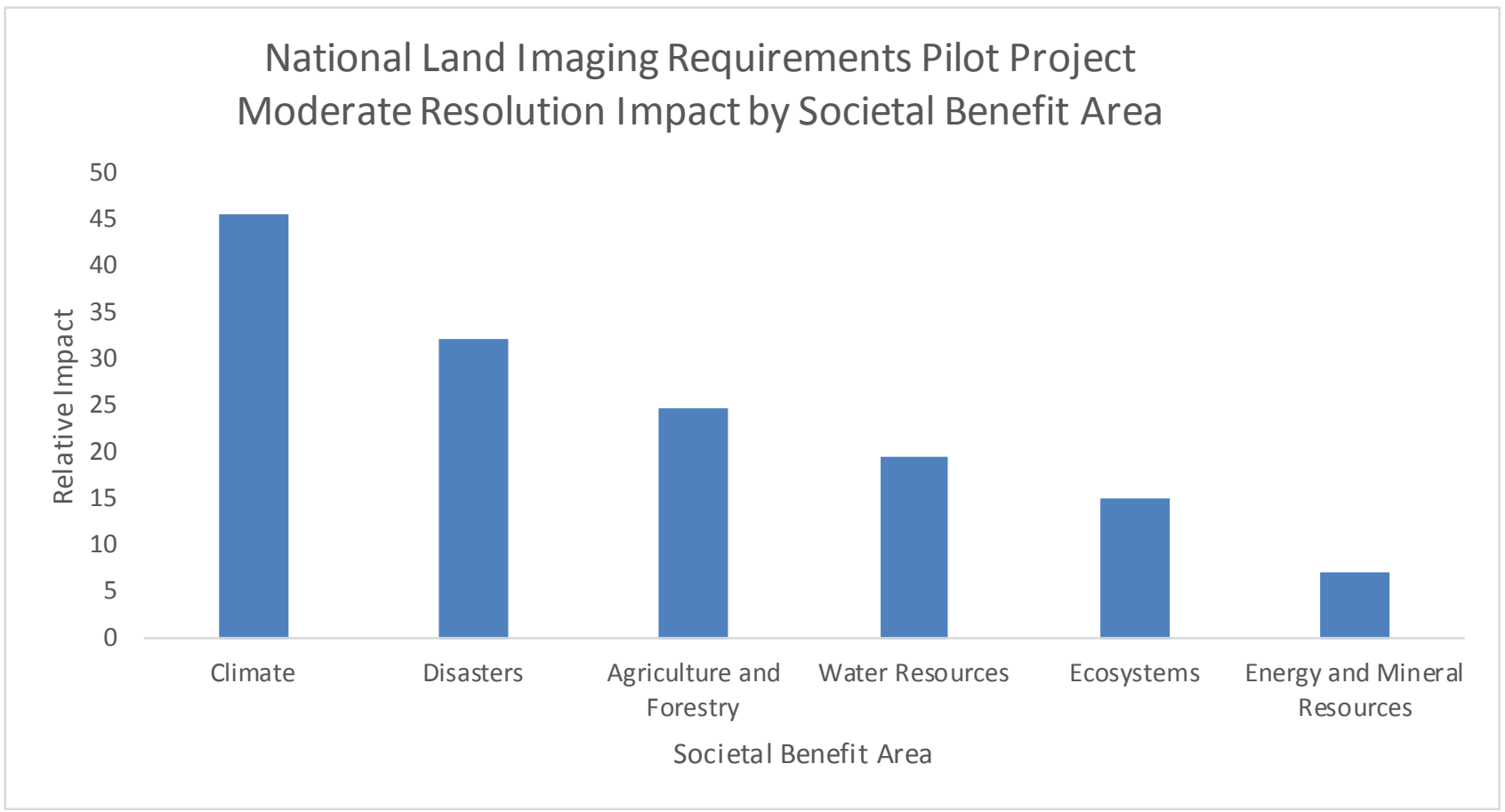

Figure 8. The relative impact of moderate resolution data on each of the Societal Benefit Areas.

The overall impact of each spectral band across all SBAs is shown in figure 9, with the relative contributions of each SBA reflected in the colored segments of each bar. Conversely, figure 10 shows the relative impact of each spectral band within each SBA.

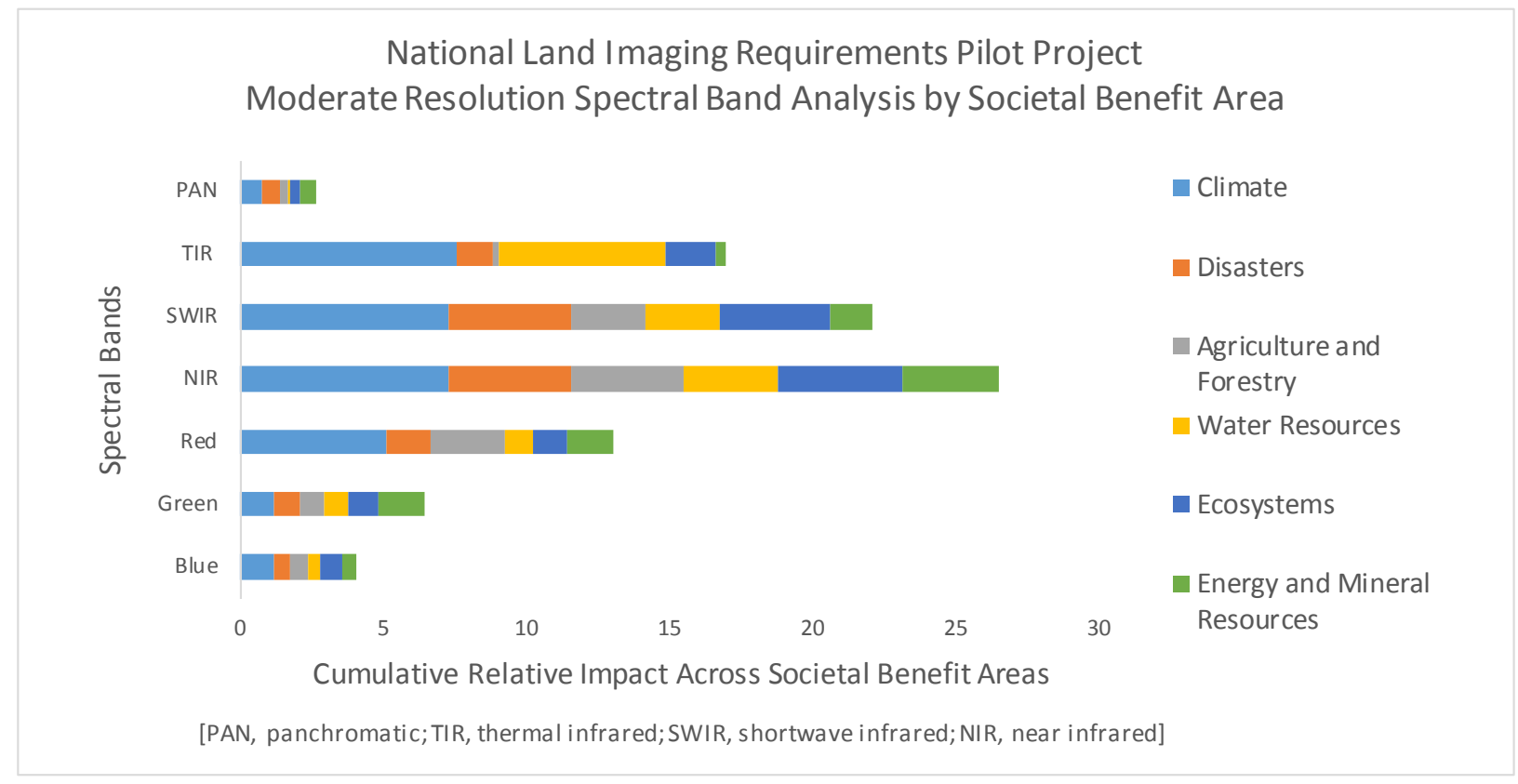

Figure 9. Cumulative impact of each of the spectral bands from moderate resolution sources across the societal benefit areas. 
To provide a comparison, the team slightly refined the results presented in the 30 May "early deliverable" for the pilot project, which provided an analysis of the relative criticality of each of the spectral bands across all SBAs from a previous value tree analysis. The corresponding spectral band analysis from the earlier study is shown in Figure 11.

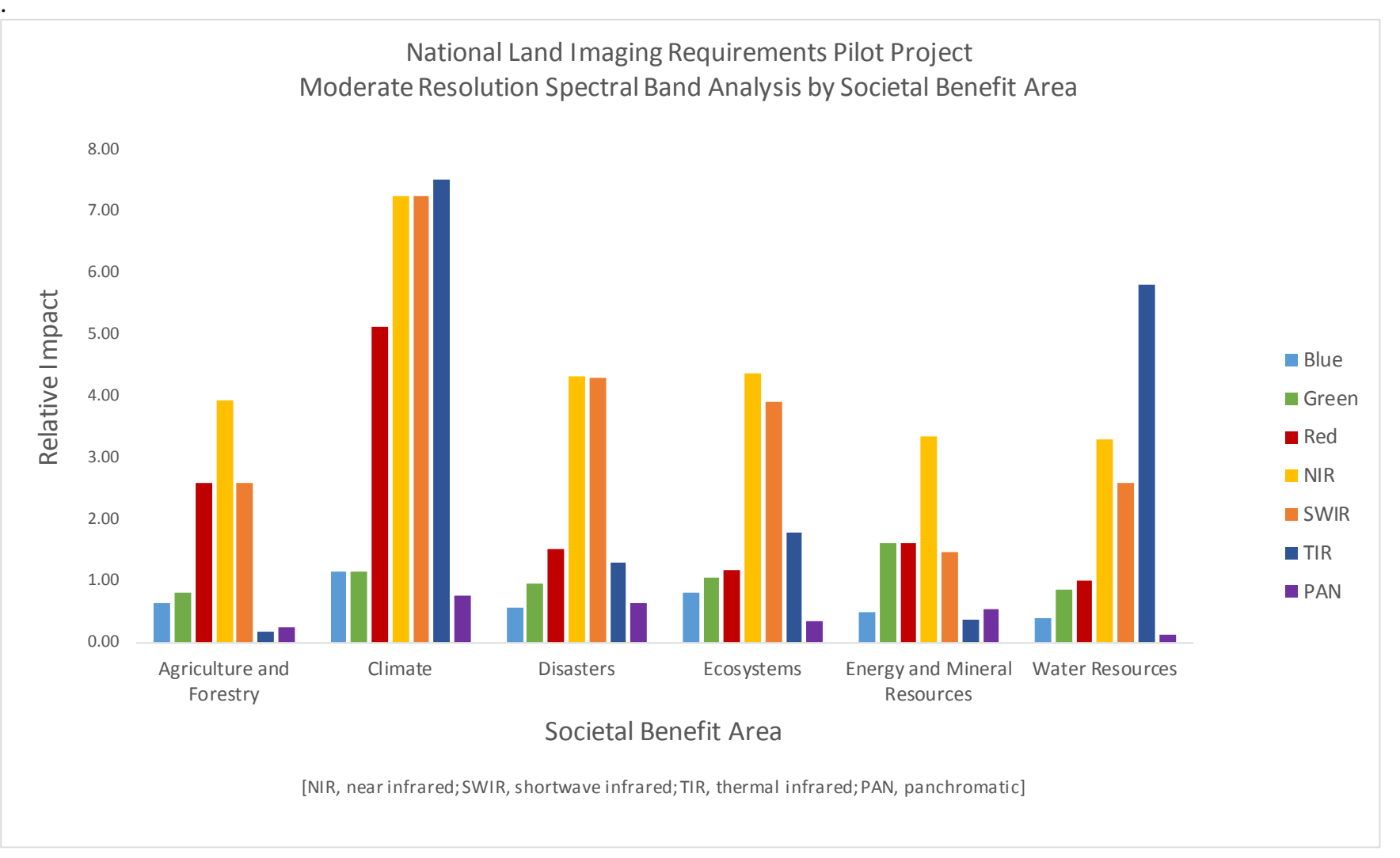

Figure 10. Impact of each of the spectral bands from moderate resolution sources within each SBA. This presentation of the data provides a picture of which SBAs are the heaviest users of moderate resolution imagery, and how similar or unique the individual SBAs are in their use of the various bands.

The scales reflected in the horizontal axes of Figure 9 and Figure 11 both showing relative impact, are quite different owing to two separate factors. First, the scope of the earlier analysis covered the gamut of Earth observing systems, such that moderate resolution multispectral imaging systems were only a small component (one among many), and therefore the impact within and across SBAs was much lower. Second, the pilot project focused on applications with known uses of multispectral imagery so the impact would be expected to be much more substantial for the chosen applications. The higher relative valuing of the thermal infrared band also likely is due to the focused nature of the pilot project. Although the scales shown are quite different, one can easily see that the relative impacts of the individual spectral bands are fairly consistent and overall the two analyses yielded fairly similar results. This outcome is not unexpected as the uses of moderate resolution multispectral imagery tend to support like applications (land cover and vegetation indices, for example). The impact of each of the spectral bands from moderate resolution sources across all of the SBAs is summarized in figure 12. 




Figure 11. Extending data from a previous Portfolio Analysis Machine ${ }^{\mathrm{TM}}$ analysis, this figure shows the cumulative impact of each of the spectral bands from moderate resolution sources across the societal benefit areas.

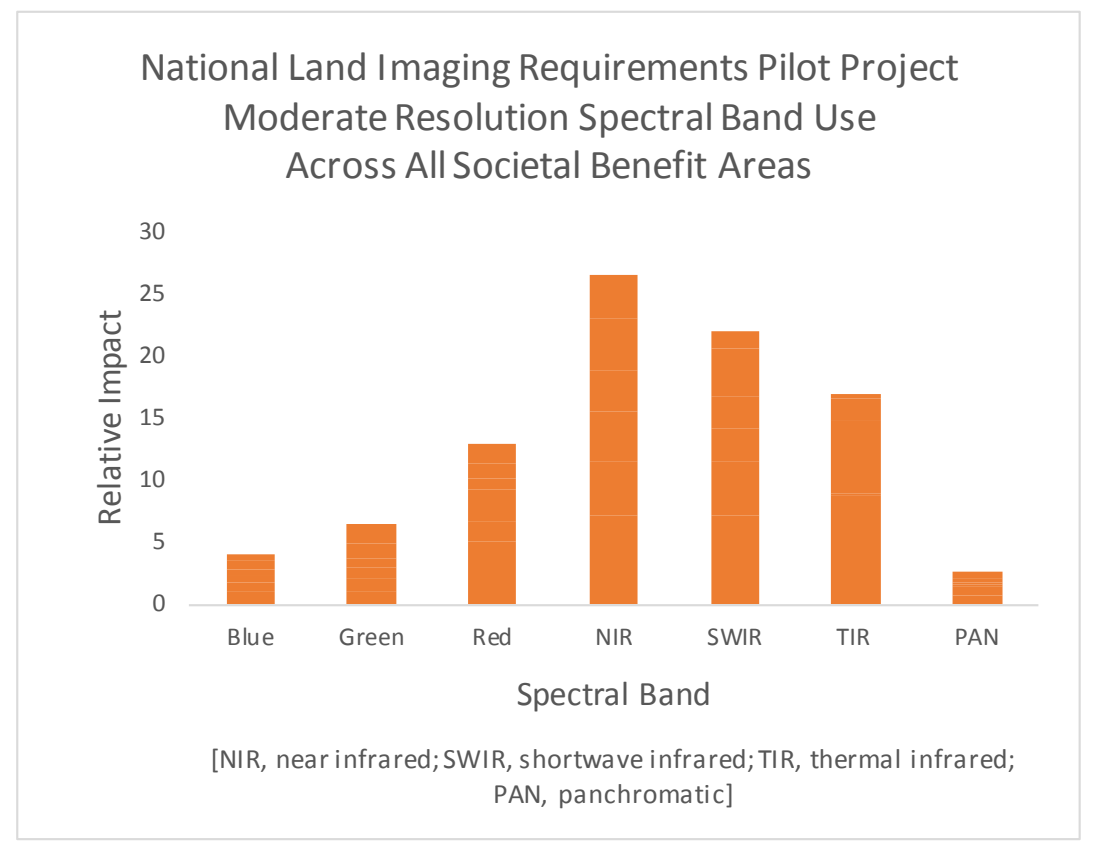

Figure 12. Impact of each of the spectral bands from moderate resolution sources across all of the societal benefit areas. From this graphic, one can see that the near infrared band has the most impact and the panchromatic band has the least impact. 


\section{User Requirements-A Preliminary Set}

The requirements elicitation part of the pilot project yielded a total of 191 user requirements, including 114 threshold requirements, 62 breakthrough requirements, and 15 target requirements (shown as a percentage in Figure 13). A summary of all requirements collected are contained in Appendix 4, Preliminary User Requirements Summary Information.

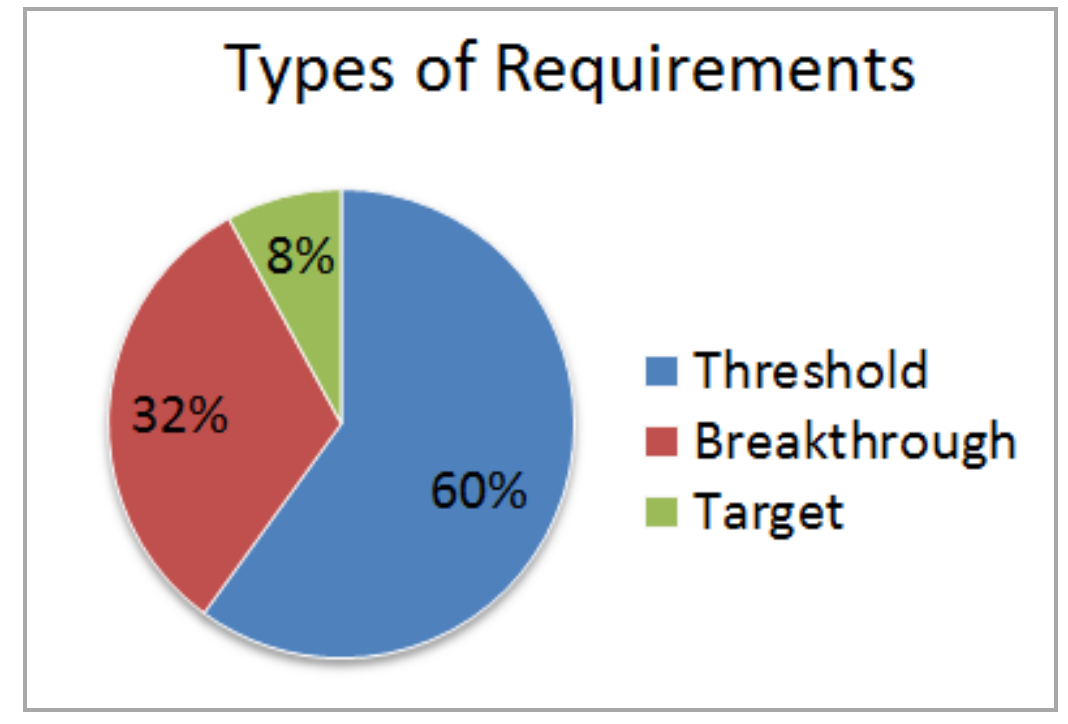

Figure 13. National Land Imaging Requirements pilot project user requirements summary by requirement type.

Of the 191 requirements, a total of 158 could be met or partially met by moderate resolution data. In cases where the resolution of a threshold requirement was specified as being greater than $120 \mathrm{~m}$ (outside of our definition of moderate resolution) but where the breakthrough or target resolution for that same requirement was specified as being between 5 and $120 \mathrm{~m}$, the set of requirements was determined to be in scope for the project and are included in this summary.

Some requirements were only developed at the threshold level. In these cases, meeting the threshold completely satisfies the need stated by the user, and any improvements to resolution, frequency, or spectrum were determined not likely to have a substantial impact on key product or service performance.

A few of the requirements captured represent the need for a derived product, such as Land Use Classes, rather than a need for EO data. The needs of downstream users of moderate resolution data represent an important set of use cases, so the team was fortunate to be able to capture a few of those types of requirements to work through the process.

\section{Geographic Coverage}

Specific information about the geographic coverage required to meet each requirement was gathered in the elicitation, however, for the purpose of this report, geographic coverage has been loosely binned into the four categories shown in Figure 14. The category "Targeted" represents cases where geographically focused, limited duration information is required, such as for disaster response or the periodic need for imagery to support surface mining compliance monitoring at individual mine sites. The category "U.S." also includes requirements that extend to Puerto Rico and U.S. island territories. 
In Figure 14, the high percentage of requirements with coverage limited to the United States simply reflects the user groups included in the pilot project elicitation. Many of the DOI and USDA subordinate organizations have responsibilities that are limited to the United States and its territories, and therefore they do not require global coverage.



Figure 14. Percentage of threshold requirements in each of the four geographic coverage categories indicated.

\section{Horizontal Resolution}

Similarly, for the purpose of this report horizontal resolution for each requirement was binned into one of seven categories: $<5 \mathrm{~m}, 5 \mathrm{~m}, \leq 15 \mathrm{~m}, \leq 30 \mathrm{~m}, \leq 60 \mathrm{~m}, 100 \mathrm{~m}$, and $>100 \mathrm{~m}$ as shown in figure 15. Again, the large proportion of requirements that can be met by data with horizontal resolutions of $30 \mathrm{~m}$ or less reflects the choice of target applications in the pilot project. 


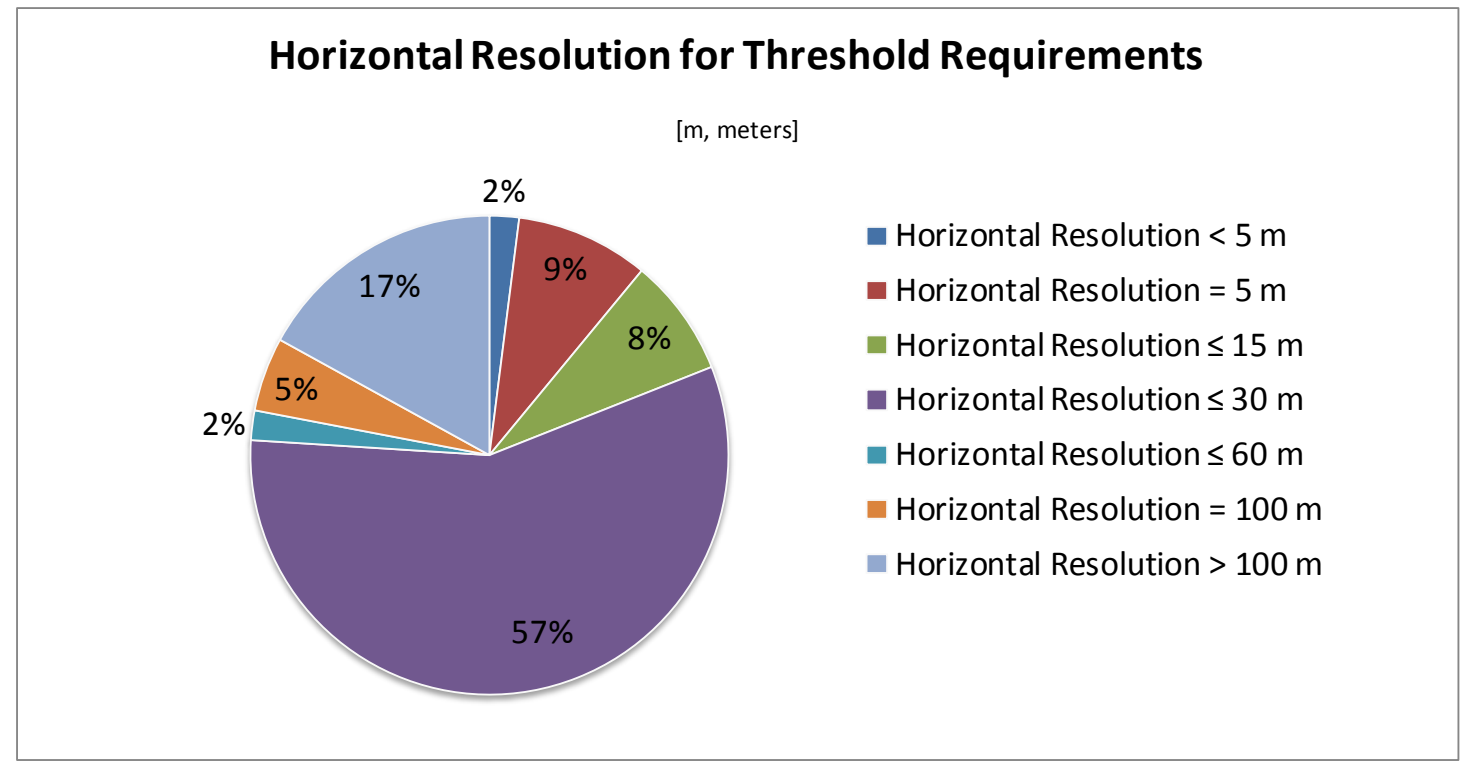

Figure 15. Percentage of threshold requirements in each of the seven horizontal resolution categories indicated.

Fifty-seven percent of the threshold requirements can be met by data that are 30 meters or less in resolution.

\section{Revisit Frequency}

In documenting user requirements, the team tried to gather information in terms of the need for data refresh at some frequency to deliver the key products or services rather than asking users to speculate what frequency of satellite overpass would yield cloud-free imagery to support their activities. For the purposes of this report, however, the team loosely binned the need for data refresh into the following categories:

$\square$ 2-day revisit: Cloud-free data needed daily or every few days

4-day revisit: Cloud-free data needed weekly

8-day revisit: Cloud-free data needed every couple of weeks

16-day revisit: Cloud-free data needed seasonally

16-day revisit: Cloud-free data needed annually or longer

The summary of revisit frequency for the set of threshold requirements using a further roll-up of the categories listed above is shown in figure 16.

Overall, 36 percent of all threshold requirements collected require less than an 8-day revisit. These data refresh needs are primarily related to applications requiring observation of plant phenological cycles during the growing season, the need to see vegetation disturbance and response in a timely manner, estimation of evapotranspiration and drought monitoring, and disaster response. 


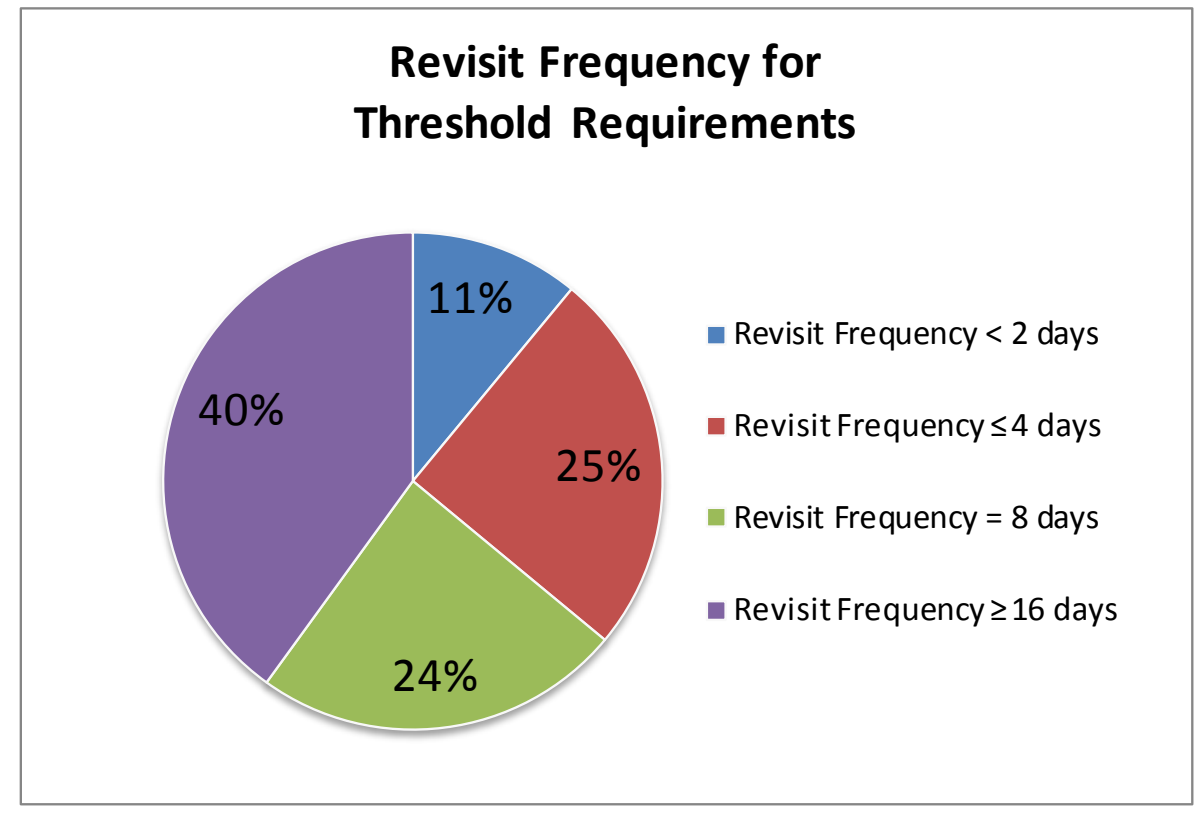

Figure 16. Revisit frequency for the 114 threshold requirements identified in the pilot project.

\section{Spectral Needs}

The need for thermal infrared data was identified in 36 percent of all requirements documented in the pilot project; however, this finding likely underestimates the need for thermal infrared data because thermal data are used to identify and remove clouds from applications using visible, near infrared (NIR) and shortwave infrared (SWIR), though not consistently called out directly. Only 14 percent of all requirements can be met by visible and NIR data alone.

Although roughly 13 percent of SMEs indicated any use of the panchromatic (PAN) band data at the threshold level (and that was often reported as sporadic/experimental), some did indicate a desire to exploit those data more fully in the future for PAN sharpening.

Several applications identified either additional parts of the spectrum that needed to be sampled, or greater spectral resolution within existing bands.

To estimate crop residue (nonphotosynthetic vegetation), additional spectral bands are needed in the SWIR portion of the spectrum. Ideally, the additional bands would be 10-50 nanometers (nm) wide, centered at $2030 \mathrm{~nm}, 2100 \mathrm{~nm}$, and $2200 \mathrm{~nm}$. The $2100 \mathrm{~nm}$ band exhibits the cellulose absorption feature, with the two other bands on the shoulders. Some research (Daughtry, C., U.S. Department of Agriculture Agricultural Research Service, written commun., 2013) has evaluated the SWIR bands that successfully operated on the Advanced Spaceborne Thermal Emission and Reflection Radiometer (ASTER) satellite for this purpose (the SWIR sensor on ASTER stopped functioning in 2008).

Adding a 7-micron thermal infrared (TIR) band would make sulfur dioxide $\left(\mathrm{SO}_{2}\right)$ and volcanic ash mapping with Landsat data possible, enhancing global aviation safety. Ultraviolet (UV) bands also are needed for mapping $\mathrm{SO}_{2}$ in the atmosphere. 
Horizontal Resolution, Revisit, and Spectral Needs Combined

Combining the attributes of resolution and revisit, of the threshold requirements netted by the pilot project, exactly 50 percent (57 requirements) can currently (2013) be met by 30-m resolution imagery at an 8-day revisit (current 2013 Landsat capability), whereas dropping to a 16-day revisit would meet only 22 percent of the requirements. A summary of these requirements by key product is provided in table 4.

Similarly, without regard for revisit frequency, 57 percent of the threshold requirements (65 requirements) can be met by data with a resolution of $15 \mathrm{~m}$ and any combination of visible and near infrared (VNIR) or SWIR bands (similar to Satellite Pour l'Observation de la Terre (SPOT) capability), however, dropping the SWIR band (similar to Disaster Monitoring Constellation (DMC) capability) would meet only 13 percent of the threshold requirements (15 requirements). This comparison is shown in table 5.

\section{Sustaining the Long-Term Calibration}

Landsat provides a unique dataset in the form of a 40-year calibrated record of the surface of the Earth (U.S. Geological Survey, 2013). Subject matter experts were not consistently asked in the pilot project elicitation about the importance of having a calibrated long-term record to support their activities. But the team did note the length of the data record where SMEs indicated it was a relevant factor. As would be expected, applications looking at long-term change were the most vocal advocates of maintaining the record, although many others had well-defined needs for a dataset that goes back at least 3 years. Some specific key products, services, and intermediate products relying upon the calibrated archive include the following:

$\square$ Monitoring Trends in Burn Severity

National Land Cover Dataset (NLCD)

National Drought Assessment

Global Land Cover 30-meter Dataset

National Land Cover Trends Assessment

National Carbon Assessment

National Crop Forecasting

Forest Resource Mapping

Sage Grouse Conservation

Actuarial Rate Maps for Crop Insurance 
Table 4. Comparison of threshold requirements met by 30-meter resolution and 8-day revisit and those requirements no longer met if revisit drops to 16 days.

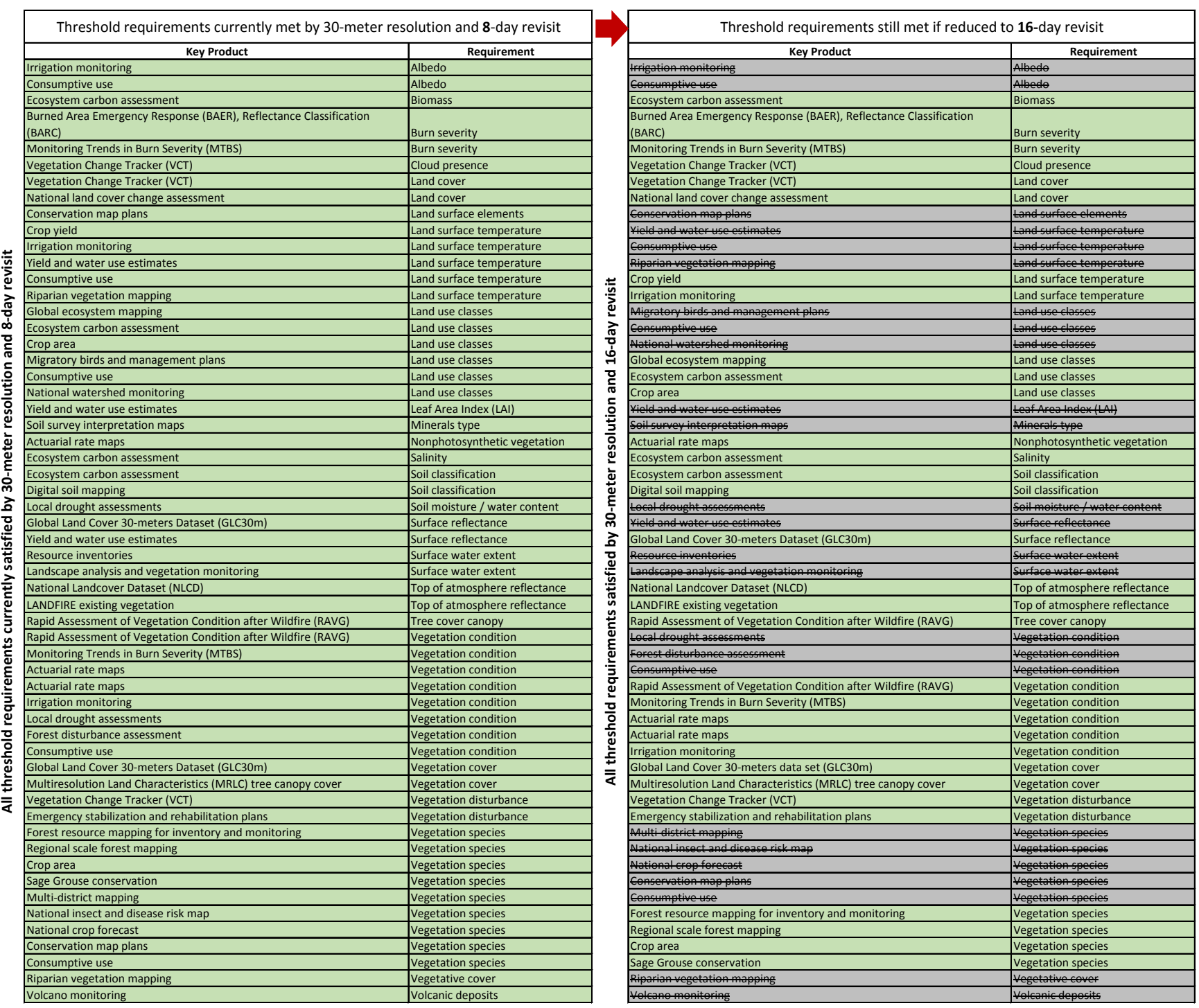


Table 5. Comparison of threshold requirements met by 15-meter resolution and any combination of visible and near infrared (VNIR) and shortwave infrared (SWIR) data, and those no longer met if SWIR is not available.

\begin{tabular}{|c|c|}
\hline \multicolumn{2}{|c|}{$\begin{array}{l}\text { Threshold requirements currently met by } 15 \text {-meter resolution and any combination of } \\
\text { visible and near infrared (VNIR) and shortwave infrared (SWIR) }\end{array}$} \\
\hline Key Product & Requirement \\
\hline Consumptive use & Albedo \\
\hline Irrigation monitoring & Albedo \\
\hline Ecosystem carbon assessment & Biomass \\
\hline $\begin{array}{l}\text { Burned Area Emergency Response (BAER), Burned Area Reflectance } \\
\text { Classification (BARC) }\end{array}$ & Burn severity \\
\hline Monitoring Trends in Burn Severity (MTBS) & Burn severity \\
\hline Emergency stabilization and rehabilitation plans & Burn severity \\
\hline National land cover change assessment & Land cover \\
\hline Disaster response & Land surface elements \\
\hline Volcano monitoring & Land surface elements \\
\hline Conservation map plans & Land surface elements \\
\hline Global ecosystem mapping & \begin{tabular}{|l} 
Land use classes \\
\end{tabular} \\
\hline Migratory birds and management plans & Land use classes \\
\hline Consumptive use & Land use classes \\
\hline National watershed monitoring & Land use classes \\
\hline Yield and water use estimates & Leaf Area Index (LAI) \\
\hline Environmental impact assessment & Mineral type \\
\hline Deposit modeling & Mineral type \\
\hline Soil survey interpretation maps & Mineral type \\
\hline Actuarial rate maps & Nonphotosynthetic vegetation \\
\hline Crop Yield & Nonphotosynthetic vegetation \\
\hline Crop residue monitoring & Nonphotosynthetic vegetation \\
\hline Crop area & Nonphotosynthetic vegetation \\
\hline Compliance monitoring investigations & Seasonally frozen ground \\
\hline Crop residue monitoring & Soil disturbance \\
\hline Global Land Cover 30-meters Dataset (GLC30m) & Surface reflectance \\
\hline Yield and water use estimates & Surface reflectance \\
\hline Actuarial rate maps & Surface water extent \\
\hline Compliance monitoring investigations & Surface water extent \\
\hline National crop forecast & Surface water extent \\
\hline Landscape analysis and vegetation monitoring & Surface water extent \\
\hline National watershed monitoring & Surface water extent \\
\hline Resource inventories & Surface water extent \\
\hline LANDFIRE existing vegetation & Top of atmosphere reflectance \\
\hline National Landcover Dataset (NLCD) & Top of atmosphere reflectance \\
\hline Rapid Assessment of Vegetation Condition after Wildfire (RAVG) & Tree cover canopy \\
\hline National drought assessment & Vegetation condition \\
\hline Phenology assessment & Vegetation condition \\
\hline Actuarial rate maps & Vegetation condition \\
\hline Actuarial rate maps & Vegetation condition \\
\hline Compliance monitoring investigations & Vegetation condition \\
\hline Determine condition of the vegetation on the rangelands & Vegetation condition \\
\hline Consumptive use & Vegetation condition \\
\hline Rapid Assessment of Vegetation Condition after Wildfire (RAVG) & Vegetation condition \\
\hline Irrigation monitoring & Vegetation condition \\
\hline Monitoring Trends in Burn Severity (MTBS) & Vegetation condition \\
\hline Irrigated land dynamics & Vegetation condition \\
\hline Forest disturbance queuing & Vegetation condition \\
\hline Forest disturbance assessment & Vegetation condition \\
\hline Global Land Cover 30-meter Dataset (GLC30m) & Vegetation cover \\
\hline Compliance monitoring investigations & Vegetation cover \\
\hline Multiresolution Land Characteristics (MRLC) tree canopy cover & Vegetation cover \\
\hline Riparian vegetation mapping & Vegetation cover \\
\hline National crop forecast & Vegetation disturbance \\
\hline Compliance monitoring investigations & Vegetation disturbance \\
\hline Emergency stabilization and rehabilitation plans & Vegetation disturbance \\
\hline Compliance monitoring investigations & Vegetation species \\
\hline Regional scale forest mapping & Vegetation species \\
\hline National Cropland Data Layer (NCDL) & Vegetation species \\
\hline Consumptive use & Vegetation species \\
\hline Riparian vegetation mapping & Vegetation species \\
\hline Sage Grouse conservation & Vegetation species \\
\hline Multi-district mapping & Vegetation species \\
\hline National insect and disease risk map & Vegetation species \\
\hline Conservation map plans & Vegetation species \\
\hline Volcano monitoring & \begin{tabular}{|l|} 
Volcanic deposits \\
\end{tabular} \\
\hline
\end{tabular}

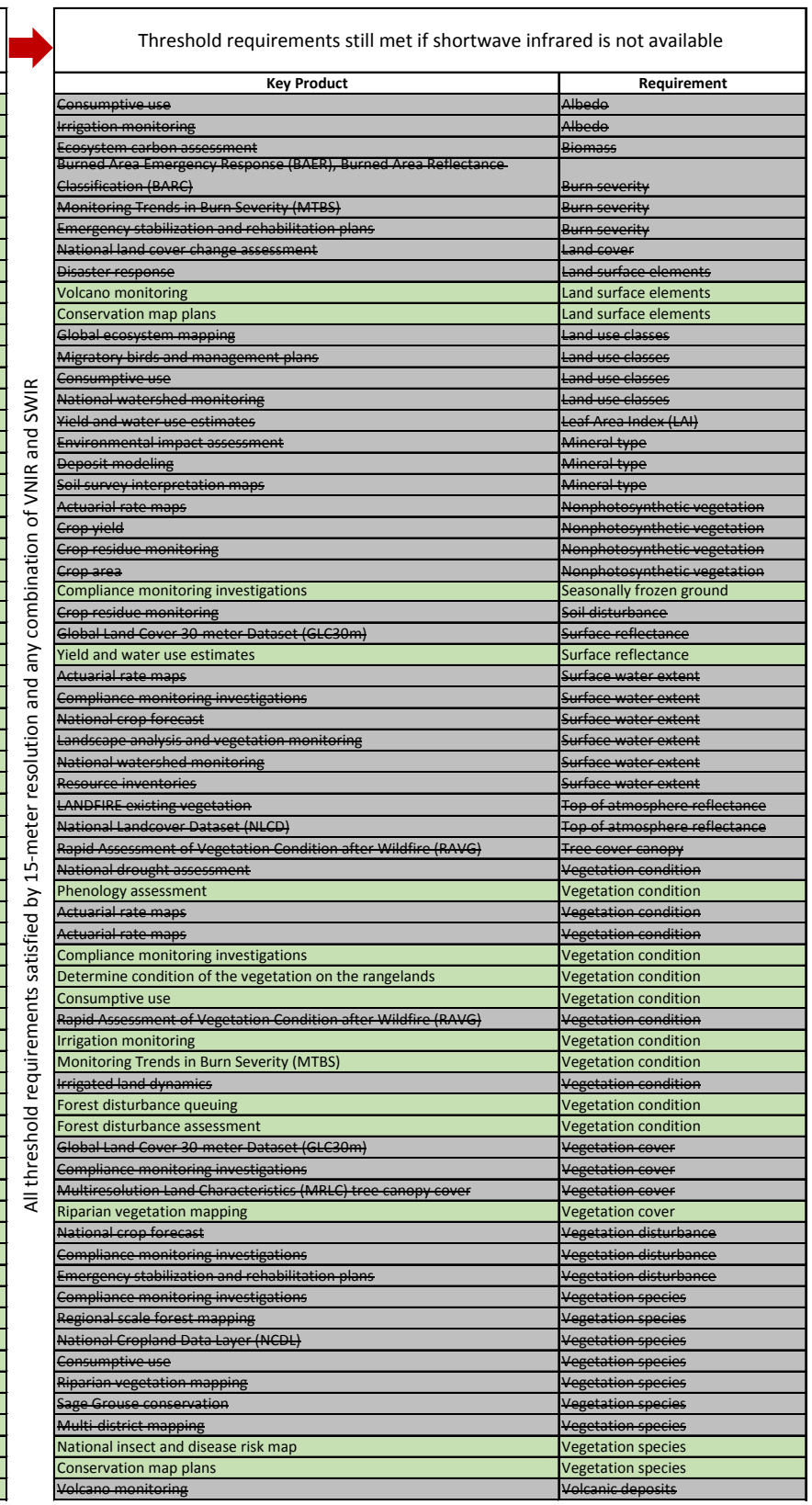

\section{Need for Concurrent Measurements}

Subject matter experts often highlighted the need for concurrent measurements to support their key products and services:

For many applications, concurrent water vapor and land surface temperature measurements are needed for calibration. 
For vegetation mapping, SMEs noted that higher accuracies are achieved when NIR and SWIR are observed together.

Water vapor and aerosols need to be concurrently measured with multispectral data to improve calibration for minerals mapping activities, with accurate water vapor measurements being the most critical.

For accurate surface energy calculations to support evapotranspiration (ET) estimation, thermal data need to be concurrently sampled with reflective bands so that temperature and albedo can be directly correlated.

To correlate surface temperature correctly to vegetated and nonvegetated areas, SMEs identified the need to have TIR and SWIR collected coincidentally. Without it, leaf area index (LAI) cannot be spatially geolocated with temperature data.

\section{Other Issues}

The limited elicitation also provided information about other unique needs and (or) community concerns. A few examples include the following:

Volcano monitoring would benefit from TIR and SWIR data at nighttime, particularly over high latitudes.

Moderate Resolution Imaging Spectroradiometer (MODIS) data are widely used because of the twice daily refresh and a reasonable resolution and swath width. The Visible Infrared Imaging Radiometer Suite (VIIRS) instrument on the Suomi National Polar-orbiting Partnership (NPP) platform has been cited as the "follow-on" capability to MODIS; however, multiple SMEs express concern over the ability of VIIRS to offer similar capability and considerable uncertainty about how and from whom data will be available.

Several SMEs indicated the need/desire for routine Landsat-derived products for surface reflectance, land surface temperature, surface water extent, and leaf area index.

\section{Limitations}

Because the set of user requirements described and analyzed in this summary report is the result of an evolving process and selective elicitations (as well as the pilot project itself), these results should not be considered a comprehensive or definitive statement of moderate resolution imaging requirements.

The nature of a process-oriented pilot project is necessarily limited in scope and a cycle of design-test-redesign-test until the desired process has been designed and tested successfully. The pilot project described in this summary report conforms to this description, recognizing that not all elements of the process were tested equally. Any shortfalls in testing and refining elements of the process will be addressed by the team before the final close-out of the pilot project.

The evolution of the elicitation and requirements development process throughout the pilot project resulted in collection of requirements information in slightly different ways from different SMEs. Although the project team does not believe the difference to be substantial, it should be noted as a limitation in the results.

To fit within the allotted time, only selected users of moderate resolution imagery in the USDA and DOI were elicited for requirements. Although the informal interview of state geospatial liaisons afforded some insight into state, local, tribal, academic, and private sector users, the large non-Federal user base of moderate resolution imagery has not been adequately covered in this pilot project.

Additionally because of time limitations, the requirements captured herein should be considered preliminary as in most cases there was time only for the initial requirements elicitation and a single 
cursory review of the initial draft requirements by SMEs. Going forward, the requirements collected during the pilot project will need to be further developed to address the appropriateness of attributes to requirement level assigned, and to further remove them from ties to current (2013) capabilities and technologies.

Lastly, the requirements described above have not been validated to assure that they are the correct and complete requirements even for this limited set of elicitations. The experience of the project team in other agencies indicates that formal validation can be a multi-month to years-long process.

The NLIR pilot project created and tested a process to elicit and develop land imaging user requirements, focusing on moderate resolution imaging needs. The development of this process yielded a preliminary sample of moderate resolution imaging requirements that have been analyzed, with the preliminary results presented in the "User Requirements-A Preliminary Set" section. Additionally, the requirements captured during the pilot project are preliminary and need further development to enable their prioritization, verification, and validation. Finally, because the set of user requirements is the result of an evolving process and selective elicitations, it should not be considered a comprehensive or definitive statement of moderate resolution imaging requirements.

\section{Summary}

This preliminary analysis of the draft user requirements gathered for the pilot project indicates close agreement with previous user requirement studies that focused on applications of moderate resolution imagery (Masek, J., Newman, T., Loveland, T., and Irons, J., unpub. data, 2012). This close agreement helps to substantiate the validity of the results. The pilot project data also reinforce existing user community knowledge that a reduction in revisit time, most notably from 16 to 8 days for Landsat, provides a substantial increase in their ability to meet land imaging frequency requirements.

Although not directly the focus of the requirements elicitation process, information collected during the pilot project also indicated user demand for higher level processed Landsat-type products; such as surface reflectance, land surface temperature, surface water extent, and leaf area index. The follow-on NLIR Project elicitation will be used to gauge the relative demand for these types of products.

This effort was highly successful in engaging land imaging users, capturing a preliminary set of user requirements, and establishing an enhanced elicitation process. This process, including lessons learned, will be used in follow-on NLIR elicitation efforts beginning in 2014. 


\section{References}

Chen, Chun-Hsien, Khoo, L.P., and Yan, W., 2002, A strategy for acquiring customer requirement patterns using laddering technique and ART2 neural network: Advanced Engineering Informatics, 16, p. 229-240.

Corbridge, C., Rugg, G., Major, N.P., Shadbolt, N.R., and Burton, A.M., 1994, Laddering: technique and tool use in knowledge acquisition: Knowledge Acquisition, 6, p. 315-341.

Environmental Protection Agency, 2011, Expert Elicitation Task Force white paper: Washington, DC, U.S. Environmental Protection Agency, 142 p.

Meyer, Mary A. and Booker, J.M., 2001, Eliciting and analyzing expert judgment - a practical guide: Philadelphia, Penn., Society for Industrial and Applied Mathematics and the American Statistical Association, 459 p.

Miller, Eric J., Crowe, J., Yapur, M., Reining, R., Schmidt, B., Ries, V., Vadnais, C., Babcock, M.R., Barrett, J., 2013, Inter-agency Earth-observation integrated analysis, in Conference on Environmental Information Processing Technologies, 29 ${ }^{\text {th }}$, Austin, Tex., American Meteorological Society.

Office of Science and Technology Policy, 2013, National strategy for civil Earth observations: Washington, DC, Executive Office of the President, $60 \mathrm{p}$.

Olsen, L.M., Major, G., Shein, K., Scialdone, J., Ritz, S., Stevens, T., Morahan, M., Aleman, A., Vogel, R., Leicester, S., Weir, H., Meaux, M., Grebas, S., Solomon, C., Holland, M., Northcutt, T., Restrepo, R.A., and Bilodeau, R., 2013, NASA/Global Change Master Directory (GCMD) Earth science keywords, Version 8.0.0.0.0: Goddard Space Flight Center, Maryland, National Aeronautics and Space Administration.

Parnell, Gregory S., Driscoll, P.J., and Henderson, D.L., eds., 2011, Decision making in systems engineering and management (2d ed.): Hoboken, NJ, Wiley, 497 p.

Schmidt, Brian K., 2011, Portfolio Analysis Machine user's guide, single year version 1.70, MP110132, Bedford, Mass., The MITRE Corporation, 131 p.

U.S. Geological Survey, 2013, Landsat—a global land-imaging mission: U.S. Geological Survey Fact Sheet 2012-3072, 4 p.

Young, Ralph R., 2004, The requirements engineering handbook: Norwood, Mass., Artech House, 254 p. 


\section{Appendix 1. Abbreviations}

\begin{tabular}{|c|c|}
\hline ALI & Advanced Land Imager \\
\hline ARS & Agriculture Research Service, U.S. Department of Agriculture \\
\hline ASTER & Advanced Spaceborne Thermal Emission and Reflection Radiometer \\
\hline AWiFS & Advanced Wide Field Sensor \\
\hline BLM & Bureau of Land Management, U.S. Department of the Interior \\
\hline BOR & Bureau of Reclamation, U.S. Department of the Interior \\
\hline CENRS & Committee on Environment, Natural Resources, and Sustainability \\
\hline DMC & Disaster Monitoring Constellation \\
\hline DOI & Department of the Interior \\
\hline DOIRSWG & Department of the Interior Remote Sensing Working Group \\
\hline EO & Earth Observation \\
\hline EOA & Earth Observation Assessment \\
\hline EORES & Earth Observation Requirements Evaluation System \\
\hline ET & Evapotranspiration \\
\hline FAQ & Frequently Asked Questions \\
\hline FAS & Foreign Agricultural Service, U.S. Department of Agriculture \\
\hline FWS & Fish and Wildlife Service, U.S. Department of the Interior \\
\hline GCMD & Global Change Master Directory \\
\hline GIS & Geographic Information System \\
\hline KPS & Key Product or Service \\
\hline LAI & Leaf Area Index \\
\hline MSA & Mission Service Area \\
\hline MODIS & Moderate Resolution Imaging Spectroradiometer \\
\hline NASA & National Aeronautic and Space Administration \\
\hline NASS & National Agricultural Statistics Service, U.S. Department of Agriculture \\
\hline NDVI & Normalized Difference Vegetation Index \\
\hline NGP & National Geospatial Program \\
\hline NIR & Near Infrared \\
\hline NLIR & National Land Imaging Requirements \\
\hline NOAA & National Oceanic and Atmospheric Administration, U.S. Department of Commerce \\
\hline NPP & National Polar-orbiting Partnership \\
\hline NRCS & Natural Resources Conservation Service, U.S. Department of Agriculture \\
\hline NSDI & National Spatial Data Infrastructure \\
\hline PALMA $^{\mathrm{TM}}$ & Portfolio Analysis Machine (The MITRE Corporation) \\
\hline PAN & Panchromatic \\
\hline RMA & Risk Management Agency, U.S. Department of Agriculture \\
\hline SBA & Societal Benefit Area \\
\hline SMES & Subject Matter Experts \\
\hline SPOT & Satellite Pour l'Observation de la Terre \\
\hline SO2 & Sulfur Dioxide \\
\hline SWIR & Short Wave Infrared \\
\hline TIR & Thermal Infrared \\
\hline UAS & Unmanned Aerial System \\
\hline USDA & United States Department of Agriculture \\
\hline USGS & United States Geological Survey \\
\hline UV & Ultraviolet \\
\hline VIIRS & Visible Infrared Imaging Radiometer Suite \\
\hline VNIR & Visible and Near-Infrared \\
\hline
\end{tabular}




\section{Appendix 2. Survey of State Geospatial Liaisons}

Geospatial Liaison Interviews_-List of Interview Questions

PART 1: Use of Remote Sensing Data (General - All Types \& Resolutions)

What are the primary uses or applications of land remote sensing data from any platform

(satellites, aircraft, UAS, ground-based, etc.) in your state(s)?

Who are the primary users? State, local, or tribal government? Academia? The private sector?

Do you have a general sense of the proportion of each?

Can you characterize the level of use for the primary applications? General categories could be:

a. Remote sensing expert (independently exploits the spectral information in remotely-sensed data; may

be developing new applications through novel use of data; well-versed in the details of its collection)

b. GIS user (leverages GIS applications to overlay and analyze remotely-sensed data; typically versed in application of the data but not in the details of its collection)

c. General user (primarily uses processed imagery, usually not integrated with analysis tools)

PART 2: Use of Remote Sensing Data (Specific to Moderate Resolution Imagery)

1. Do any of the remote sensing applications identified in PART 1 specifically use moderate resolution (5 to 120 meters) satellite imagery such as from Landsat? If so, which ones? (If not, skip to PART 3)

Generally, how well does the available moderate resolution imagery satisfy the needs or requirements for this type of data? (1 to 100: See rating scale below.) The score may be an overall score, or a score for each user application. Please feel free to provide more details.

\begin{tabular}{|c|c|l|}
\hline \multicolumn{3}{|c|}{ Performance / Satisfaction Scale } \\
\hline 100 & Ideal & Meets all requirements and exceeds some \\
\hline 90 & Fully Satisfied & Meets all requirements \\
\hline 80 & Good & Meets all major requirements with minor limitations \\
\hline 70 & & \\
\hline 60 & Fair & Meets most major requirements, with significant limitations \\
\hline 50 & & \\
\hline 40 & Poor & Fails to meet many major requirements, but provides some value \\
\hline 30 & & \\
\hline 20 & Very Poor & Fails to meet most major requirements, but provides minor value \\
\hline 10 & & \\
\hline 1 & No Capability & Provides no value \\
\hline
\end{tabular}

Do you have a sense of any unmet needs that could potentially be addressed by moderate resolution satellite imagery, products, or services? Would changes to certain characteristics of the data (coverage, resolution, frequency, etc.) make it more useful in meeting these 
needs? Which of the characteristics, if improved, would have the biggest impact on the usefulness of the data?

For the users and activities of which you are aware, is there primarily a steady, persistent need for a core set of data, or is the need more project-oriented and variable?

Do you have a sense of how user needs may be changing? In the near future, mid-term, or longer term? If yes, please describe.

PART 3: Data Types/Formats and Software

1. What data types/formats and software applications are most common in the use of remotely sensed imagery in your state(s)?

Are there any known limitations regarding data and applications (e.g., ease of access, bandwidth limitations, formats, excessive pre-preprocessing steps, interoperability with other sources)? Do you have suggestions for improved data or software services?

PART 4: Further Assistance

1. Are you aware of any particular professional groups or associations who may be sources of additional information or may be interested in participating in a user-needs workshop or hosting a user-needs session in one of their conferences or similar activities?

The Federal Advisory Committee Act and the Paperwork Reduction Act limit the direct solicitation of information from non-Federal users.

a. Do you feel that you can adequately represent the users in your area of responsibility in additional elicitations of the uses of and requirements for moderate resolution imagery?

b. Are you willing to participate in or facilitate a more in-depth assessment of uses of moderate resolution imagery and requirements development? 


\section{Appendix 3. Societal Benefit Area Definitions}

The societal benefit areas (SBAs) as defined in this report follow the definitions established in the National Strategy for Civil Earth Observations (Office of Science and Technology Policy, 2013). The plan lists 12 SBAs and the reference measurements that underpin them:

Agriculture and Forestry-Supporting sustainable agriculture and forestry. Biodiversity - Understanding and conserving biodiversity.

Climate-Understanding, assessing, predicting, mitigating, and adapting to climate variability and related global change.

Disasters-Reducing loss of life, property, and ecosystem damage from natural and humaninduced disasters.

Ecosystems (Terrestrial and Freshwater) —-Improving the management and protection of terrestrial and freshwater ecosystems.

Energy and Mineral Resources-Improving the identification and management of energy and mineral resources.

Human Health-Understanding environmental factors affecting human health and wellbeing.

$\square$ Ocean and Coastal Resources and Ecosystems - Understanding and protecting ocean, coastal, and Great Lakes populations and resources, including fisheries, aquaculture, and marine ecosystems.

Space Weather-Understanding, assessing, predicting, and mitigating the effects of space weather on technological systems, including satellites, power grids, communications, and navigation.

Transportation-Improving the safety and efficiency of all modes of transportation, including air, highway, railway, and marine.

Water Resources-Improving water resource management through better understanding and monitoring of the water cycle.

$\square$ Weather-Improving weather information, forecasting, and warning.

Reference Measurements-Improving reference measurements - the underpinnings of all the SBAs - such as geodesy, bathymetry, topography, geolocation, and the fundamental measurement systems and standards supporting them.

These SBAs are interconnected and include scientific research, economic activities, and environmental and social domains. Multiple SBAs share observational requirements, and societal benefits accrue from Earth observations that inform scientific research, policy, and decisionmaking. Earth observations also support critical government functions, such as the continuity of national government and the protection of life and property. 


\section{Appendix 4. Preliminary User Requirements Summary Information}

\section{National Land Imaging Requirements Pilot Project}

Preliminary Threshold and Breakthrough User Requirements Summary - Resolution and Revisit

\begin{tabular}{|c|c|c|c|c|c|c|c|c|c|c|c|c|c|}
\hline \multicolumn{3}{|c|}{ [m, meters; dy, days; blue denotes threshold level; red denotes breakthrough level] } & \multicolumn{7}{|c|}{ Resolution } & \multicolumn{4}{|c|}{ Revisit } \\
\hline Mission Service Area (MSA) & Supported Key Product or Service (KPS) & Requirement & $\begin{array}{l}E \\
\stackrel{E}{n} \\
v\end{array}$ & $\begin{array}{c}E \\
\text { in } \\
\end{array}$ & \begin{tabular}{|c|}
$E$ \\
$n$ \\
I \\
vi \\
\end{tabular} & $\begin{array}{l}\varepsilon \\
0 \\
m_{\mathrm{V}} \\
\mathrm{v}\end{array}$ & $\begin{array}{l}\varepsilon \\
8 \\
8 \\
\text { Vi } \\
\end{array}$ & $\begin{array}{l}\varepsilon \\
8 \\
8 \\
\mathrm{v} \\
\mathrm{v} \\
\end{array}$ & $\begin{array}{c}\varepsilon \\
8 \\
-1 \\
\Lambda \\
\end{array}$ & $\begin{array}{l}3 \\
0 \\
i \\
v \\
\end{array}$ & $\begin{array}{l}z \\
\dot{z} \\
\dot{v} \\
v_{1} \\
\end{array}$ & $\begin{array}{l}z \\
\infty \\
\infty \\
\text { vi }\end{array}$ & $\begin{array}{l}3 \\
0 \\
0 \\
-1 \\
v \\
v\end{array}$ \\
\hline Water management and delivery & Consumptive use & Albedo & & & & & & & & & & & \\
\hline Land change products & Irrigation monitoring & Albedo & & & & & & & & & & & \\
\hline $\begin{array}{l}\text { Climate and land use change / land } \\
\text { carbon research }\end{array}$ & Ecosystem carbon assessment & Biomass & & & & & & & & & & & \\
\hline $\begin{array}{l}\text { Assessment of forest affected by } \\
\text { abiotic agents }\end{array}$ & $\begin{array}{l}\text { Burned Area Emergency Response } \\
\text { (BAER), Burned Area Reflectance } \\
\text { Classification (BARC) }\end{array}$ & Burn severity & & & & & & & & & & & \\
\hline $\begin{array}{l}\text { Assessment of forest affected by } \\
\text { abiotic agents }\end{array}$ & $\begin{array}{l}\text { Monitoring Trends in Burn Severity } \\
\text { (MTBS) }\end{array}$ & Burn severity & & & & & & & & & & & \\
\hline Inventory and monitoring & $\begin{array}{l}\text { Emergency stabilization and } \\
\text { rehabilitation plans }\end{array}$ & Burn severity & & & & & & & & & & & \\
\hline $\begin{array}{l}\text { Climate and land use change / land } \\
\text { carbon research }\end{array}$ & Vegetation Change Tracker (VCT) & Cloud presence & & & & & & & & & & & \\
\hline Volcanoes & Volcano monitoring & Dust / ash / smoke & & & & & & & & & & & \\
\hline Volcanoes & Volcano assessment & Dust / ash / smoke & & & & & & & & & & & \\
\hline Volcanoes & Volcano research & $\begin{array}{l}\text { Eruption dynamics / lahars and } \\
\text { debris flow }\end{array}$ & & & & & & & & & & & \\
\hline Volcanoes & Volcano assessment & Eruption dynamics / pyroclastic flow & & & & & & & & & & & \\
\hline Volcanoes & Volcano assessment & $\begin{array}{l}\text { Eruption dynamics / lava speed / } \\
\text { flow }\end{array}$ & & & & & & & & & & & \\
\hline $\begin{array}{l}\text { Climate and land use change / land } \\
\text { carbon research }\end{array}$ & Vegetation Change Tracker (VCT) & Land cover & & & & & & & & & & & \\
\hline $\begin{array}{l}\text { Climate and land use change / land } \\
\text { change products }\end{array}$ & $\begin{array}{l}\text { National land cover change } \\
\text { assessment }\end{array}$ & Land cover & & & & & & & & & & & \\
\hline Regulating coal mines & $\begin{array}{l}\text { Contemporaneous reclamation } \\
\text { monitoring }\end{array}$ & Land surface elements & & & & & & & & & & & \\
\hline Regulating coal mines & $\begin{array}{l}\text { Monitoring long-term restoration of } \\
\text { mined areas }\end{array}$ & Land surface elements & & & & & & & & & & & \\
\hline Soil and water conservation & Disaster response & Land surface elements & & & & & & & & & & & \\
\hline Soil and water conservation & Disaster response & Land surface elements & & & & & & & & & & & \\
\hline Volcanoes & Volcano monitoring & Land surface elements & & & & & & & & & & & \\
\hline Soil and water conservation & Conservation map plans & Land surface elements & & & & & & & & & & & \\
\hline Global crop forecasting & Crop yield & Land surface temperature & & & & & & & & & & & \\
\hline
\end{tabular}


Preliminary Threshold and Breakthrough User Requirements Summary - Resolution and Revisit--Cont.




Preliminary Threshold and Breakthrough User Requirements Summary - Resolution and Revisit--Cont.

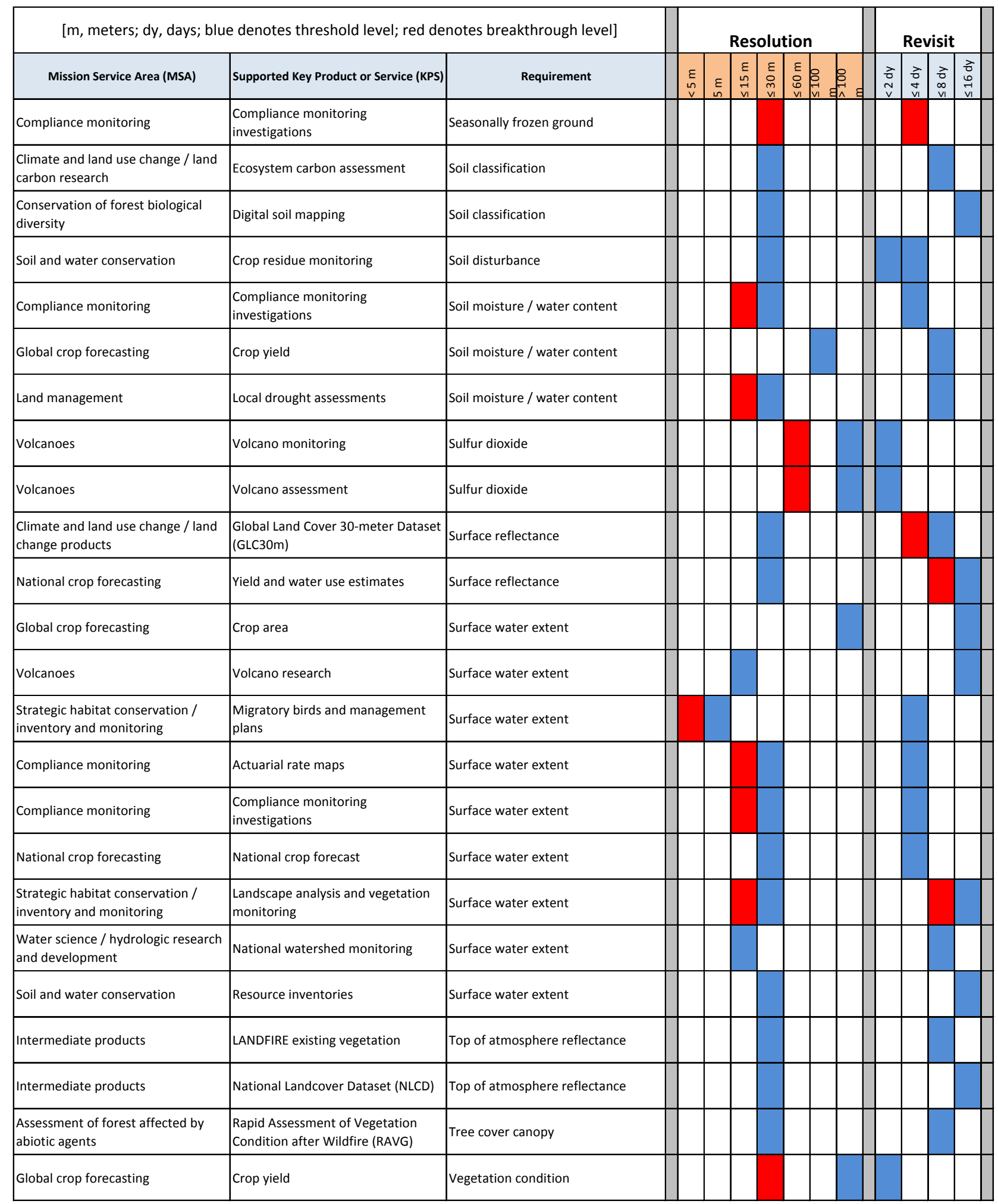


Preliminary Threshold and Breakthrough User Requirements Summary - Resolution and Revisit--Cont.

\begin{tabular}{|c|c|c|c|c|c|c|c|c|c|c|c|c|c|}
\hline \multicolumn{3}{|c|}{ [m, meters; dy, days; blue denotes threshold level; red denotes breakthrough level] } & \multicolumn{7}{|c|}{ Resolution } & \multicolumn{4}{|c|}{ Revisit } \\
\hline Mission Service Area (MSA) & Supported Key Product or Service (KPS) & Requirement & $\begin{array}{c}E \\
\text { in } \\
v\end{array}$ & $\begin{array}{c}\varepsilon \\
n\end{array}$ & $\begin{array}{c}E \\
\sim \\
\sim \\
v i \\
\end{array}$ & 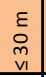 & 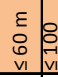 & $\underset{8}{8}$ & $\sum_{0}$ & $\begin{array}{l}3 \\
\text { z } \\
\text { v } \\
\end{array}$ & $\begin{array}{l}\vec{z} \\
0 \\
\dot{1} \\
\mathbf{v}_{1} \\
\end{array}$ & $\begin{array}{l}3 \\
0 \\
\text { vi } \\
\end{array}$ & $\begin{array}{l}3 \\
0 \\
0 \\
0 \\
v 1 \\
\end{array}$ \\
\hline Global crop forecasting & Crop yield & Vegetation condition & & & & & & & & & & & \\
\hline Global crop forecasting & Rapid response & Vegetation condition & & & & & & & & & & & \\
\hline Land management & Local drought assessments & Vegetation condition & & & & & & & & & & & \\
\hline National crop forecasting & National crop forecast & Vegetation condition & & & & & & & & & & & \\
\hline $\begin{array}{l}\text { Climate and land use change / land } \\
\text { change products }\end{array}$ & National drought assessment & Vegetation condition & & & & & & & & & & & \\
\hline $\begin{array}{l}\text { Climate and land use change / land } \\
\text { change products }\end{array}$ & Phenology assessment & Vegetation condition & & & & & & & & & & & \\
\hline Compliance monitoring & Actuarial rate maps & Vegetation condition & & & & & & & & & & & \\
\hline Compliance monitoring & Actuarial rate maps & Vegetation condition & & & & & & & & & & & \\
\hline Compliance monitoring & $\begin{array}{l}\text { Compliance monitoring } \\
\text { investigations }\end{array}$ & Vegetation condition & & & & & & & & & & & \\
\hline Compliance monitoring & $\begin{array}{l}\text { Determine condition of the } \\
\text { vegetation on the rangelands }\end{array}$ & Vegetation condition & & & & & & & & & & & \\
\hline Water management and delivery & Consumptive use & Vegetation condition & & & & & & & & & & & \\
\hline $\begin{array}{l}\text { Assessment of forest affected by } \\
\text { abiotic agents }\end{array}$ & $\begin{array}{l}\text { Rapid Assessment of Vegetation } \\
\text { Condition after Wildfire (RAVG) }\end{array}$ & Vegetation condition & & & & & & & & & & & \\
\hline Land change products & Irrigation monitoring & Vegetation condition & & & & & & & & & & & \\
\hline $\begin{array}{l}\text { Maintenance of ecosystem health } \\
\text { and safety }\end{array}$ & Forest disturbance assessment & Vegetation condition & & & & & & & & & & & \\
\hline $\begin{array}{l}\text { Assessment of forest affected by } \\
\text { abiotic agents }\end{array}$ & $\begin{array}{l}\text { Monitoring Trends in Burn Severity } \\
\text { (MTBS) }\end{array}$ & Vegetation condition & & & & & & & & & & & \\
\hline $\begin{array}{l}\text { Climate and land use change / land } \\
\text { change products }\end{array}$ & Irrigated land dynamics & Vegetation condition & & & & & & & & & & & \\
\hline $\begin{array}{l}\text { Maintenance of ecosystem health } \\
\text { and safety }\end{array}$ & Forest disturbance queing & Vegetation condition & & & & & & & & & & & \\
\hline $\begin{array}{l}\text { Maintenance of ecosystem health } \\
\text { and safety }\end{array}$ & Forest disturbance assessment & Vegetation condition & & & & & & & & & & & \\
\hline $\begin{array}{l}\text { Climate and land use change / land } \\
\text { change products }\end{array}$ & $\begin{array}{l}\text { Global Land Cover 30-meter Dataset } \\
(\text { GLC30m) }\end{array}$ & Vegetation cover & & & & & & & & & & & \\
\hline Compliance monitoring & $\begin{array}{l}\text { Compliance monitoring } \\
\text { investigations }\end{array}$ & Vegetation cover & & & & & & & & & & & \\
\hline $\begin{array}{l}\text { Conservation of forest biological } \\
\text { diversity }\end{array}$ & $\begin{array}{l}\text { Multiresolution land characteristics } \\
\text { tree canopy cover }\end{array}$ & Vegetation cover & & & & & & & & & & & \\
\hline Water management and delivery & Riparian vegetation mapping & Vegetation cover & & & & & & & & & & & \\
\hline Mineral resources & Environmental impact assessment & Vegetation cover & & & & & & & & & & & \\
\hline $\begin{array}{l}\text { Climate and land use change / land } \\
\text { carbon research }\end{array}$ & Vegetation Change Tracker (VCT) & Vegetation disturbance & & & & & & & & & & & \\
\hline
\end{tabular}


Preliminary Threshold and Breakthrough User Requirements Summary - Resolution and Revisit--Cont.

\begin{tabular}{|c|c|c|c|c|c|c|c|c|c|c|c|c|c|}
\hline \multicolumn{3}{|c|}{ [m, meters; dy, days; blue denotes threshold level; red denotes breakthrough level] } & \multicolumn{7}{|c|}{ Resolution } & \multicolumn{4}{|c|}{ Revisit } \\
\hline Mission Service Area (MSA) & Supported Key Product or Service (KPS) & Requirement & $\begin{array}{c}\varepsilon \\
\text { in } \\
\vee \\
\end{array}$ & $\begin{array}{c}\varepsilon \\
\text { in } \\
\end{array}$ & \begin{tabular}{|c|}
$\varepsilon$ \\
$n$ \\
$\mathrm{v}$ \\
$\mathrm{v}$ \\
\end{tabular} & \begin{tabular}{l|l}
$\varepsilon$ \\
0 \\
$\infty$ \\
$v_{1}$ \\
\end{tabular} & \begin{tabular}{l|l}
$\varepsilon$ & \\
8 & 0 \\
$\mathrm{~B}$ & $\mathrm{v}$ \\
$\mathrm{v}$ & $\mathrm{v}$ \\
\end{tabular} & $\begin{array}{ll}8 \\
\\
v_{1}\end{array}$ & 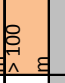 & $\begin{array}{l}3 \\
0 \\
v \\
v\end{array}$ & $\begin{array}{l}3 \\
0 \\
0 \\
\text { vi } \\
\end{array}$ & $\begin{array}{l}\vec{z} \\
\infty \\
\text { vı } \\
\end{array}$ & $\begin{array}{l}z \\
0 \\
0 \\
0 \\
v 1 \\
\end{array}$ \\
\hline National crop forecasting & National crop forecast & Vegetation disturbance & & & & & & & & & & & \\
\hline Compliance monitoring & $\begin{array}{l}\text { Compliance monitoring } \\
\text { investigations }\end{array}$ & Vegetation disturbance & & & & & & & & & & & \\
\hline Inventory and monitoring & $\begin{array}{l}\text { Emergency stabilization and } \\
\text { rehabilitation plans }\end{array}$ & Vegetation disturbance & & & & & & & & & & & \\
\hline $\begin{array}{l}\text { Conservation of forest biological } \\
\text { diversity }\end{array}$ & $\begin{array}{l}\text { Forest resource mapping for } \\
\text { inventory and monitoring }\end{array}$ & Vegetation species & & & & & & & & & & & \\
\hline Global crop forecasting & Crop area & Vegetation species & & & & & & & & & & & \\
\hline National crop forecasting & National crop forecast & Vegetation species & & & & & & & & & & & \\
\hline Compliance monitoring & $\begin{array}{l}\text { Compliance monitoring } \\
\text { investigations }\end{array}$ & Vegetation species & & & & & & & & & & & \\
\hline $\begin{array}{l}\text { Conservation of forest biological } \\
\text { diversity }\end{array}$ & Regional scale forest mapping & Vegetation species & & & & & & & & & & & \\
\hline Intermediate products & National Cropland Data Layer (NCDL) & Vegetation species & & & & & & & & & & & \\
\hline National crop forecasting & $\begin{array}{l}\text { National Agricultural Statistics } \\
\text { Service area sampling frame }\end{array}$ & Vegetation species & & & & & & & & & & & \\
\hline Water management and delivery & Consumptive use & Vegetation species & & & & & & & & & & & \\
\hline Water management and delivery & Riparian vegetation mapping & Vegetation species & & & & & & & & & & & \\
\hline Inventory and monitoring & Sage Grouse conservation & Vegetation species & & & & & & & & & & & \\
\hline Land management & Detailed vegetation classification & Vegetation species & & & & & & & & & & & \\
\hline Land management & Multi-district mapping & Vegetation species & & & & & & & & & & & \\
\hline $\begin{array}{l}\text { Maintenance of ecosystem health } \\
\text { and safety }\end{array}$ & $\begin{array}{l}\text { National Insect and Disease Risk } \\
\text { Map }\end{array}$ & Vegetation species & & & & & & & & & & & \\
\hline Soil and water conservation & Conservation map plans & Vegetation species & & & & & & & & & & & \\
\hline Mineral resources & Environmental impact assessment & Vegetation type & & & & & & & & & & & \\
\hline Volcanoes & Hazards communication & Volcanic activity & & & & & & & & & & & \\
\hline Volcanoes & Volcano monitoring & Volcanic deposits & & & & & & & & & & & \\
\hline $\begin{array}{l}\text { Strategic habitat conservation / } \\
\text { inventory and monitoring }\end{array}$ & $\begin{array}{l}\text { Landscape analysis and vegetation } \\
\text { monitoring }\end{array}$ & Wetland classification & & & & & & & & & & & \\
\hline Global crop forecasting & Rapid response & Wildfires & & & & & & & & & & & \\
\hline
\end{tabular}


National Land Imaging Requirements Pilot Project

Preliminary Threshold and Breakthrough User Requirements Summary - Spectral Bands

\begin{tabular}{|c|c|c|c|c|c|c|c|c|c|c|c|c|}
\hline \multicolumn{3}{|c|}{$\begin{array}{l}\text { [NIR, near infrared; SWIR, shortwave infrared; TIR, thermal infrared; PAN, panchromatic; UV, ultraviolet; blue cell denotes } \\
\text { threshold level; red cell denotes breakthrough level; purple cell denotes SWIR bands currently used but additional bands } \\
\text { needed] }\end{array}$} & \multicolumn{10}{|c|}{ Spectral Bands } \\
\hline Mission Service Area (MSA) & $\begin{array}{l}\text { Supported Key Product or Service } \\
\text { (KPS) }\end{array}$ & Requirement & $\frac{\varrho}{\infty}$ & ญे & $\begin{array}{l}\bar{d} \\
\mathbb{x}\end{array}$ & $\stackrel{\cong}{\Sigma}$ & 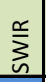 & $\stackrel{\cong}{\models}$ & $\begin{array}{l}z \\
a \\
a\end{array}$ & 3 & $\frac{3}{\overline{0}}$ & రृ \\
\hline Water management and delivery & Consumptive use & Albedo & & & & & & & & & & \\
\hline $\begin{array}{l}\text { Climate and land use change / land } \\
\text { carbon research }\end{array}$ & Ecosystem carbon assessment & Biomass & & & & & & & & & & \\
\hline $\begin{array}{l}\text { Assessment of forest affected by } \\
\text { abiotic agents }\end{array}$ & $\begin{array}{l}\text { Burned Area Emergency Response } \\
\text { (BAER), Burned Area Reflectance } \\
\text { Classification (BARC) }\end{array}$ & Burn severity & & & & & & & & & & \\
\hline $\begin{array}{l}\text { Assessment of forest affected by } \\
\text { abiotic agents }\end{array}$ & $\begin{array}{l}\text { Monitoring Trends in Burn Severity } \\
\text { (MTBS) }\end{array}$ & Burn severity & & & & & & & & & & \\
\hline Inventory and monitoring & $\begin{array}{l}\text { Emergency stabilization and } \\
\text { rehabilitation plans }\end{array}$ & Burn severity & & & & & & & & & & \\
\hline $\begin{array}{l}\text { Climate and land use change / land } \\
\text { carbon research }\end{array}$ & Vegetation Change Tracker (VCT) & Cloud presence & & & & & & & & & & \\
\hline Volcanoes & Volcano monitoring & Dust / ash / smoke & & & & & & & & & & \\
\hline Volcanoes & Volcano assessment & Dust / ash / smoke & & & & & & & & & & \\
\hline Volcanoes & Volcano research & $\begin{array}{l}\text { Eruption dynamics / lahars } \\
\text { and debris flow }\end{array}$ & & & & & & & & & & \\
\hline Volcanoes & Volcano assessment & $\begin{array}{l}\text { Eruption dynamics / } \\
\text { pyroclastic flow }\end{array}$ & & & & & & & & & & \\
\hline $\begin{array}{l}\text { Climate and land use change / land } \\
\text { carbon research }\end{array}$ & Vegetation Change Tracker (VCT) & Land cover & & & & & & & & & & \\
\hline $\begin{array}{l}\text { Climate and land use change / land } \\
\text { change products }\end{array}$ & $\begin{array}{l}\text { National Land Cover Change } \\
\text { Assessment }\end{array}$ & Land cover & & & & & & & & & & \\
\hline Regulating coal mines & $\begin{array}{l}\text { Contemporaneous reclamation } \\
\text { monitoring }\end{array}$ & Land surface elements & & & & & & & & & & \\
\hline Regulating coal mines & $\begin{array}{l}\text { Monitoring long-term restoration of } \\
\text { mined areas }\end{array}$ & Land surface elements & & & & & & & & & & \\
\hline Soil and water conservation & Disaster response & Land surface elements & & & & & & & & & & \\
\hline Soil and water conservation & Disaster response & Land surface elements & & & & & & & & & & \\
\hline Volcanoes & Volcano monitoring & Land surface elements & & & & & & & & & & \\
\hline Soil and water conservation & Conservation map plans & Land surface elements & & & & & & & & & & \\
\hline Global crop forecasting & Crop yield & Land surface temperature & & & & & & & & & & \\
\hline Land change products & Irrigation monitoring & Land surface temperature & & & & & & & & & & \\
\hline
\end{tabular}


Preliminary Threshold and Breakthrough User Requirements Summary - Spectral Bands--Cont.

\begin{tabular}{|c|c|c|c|c|c|c|c|c|c|c|c|c|}
\hline \multicolumn{3}{|c|}{$\begin{array}{l}\text { [NIR, near infrared; SWIR, shortwave infrared; TIR, thermal infrared; PAN, panchromatic; UV, ultraviolet; blue cell denotes } \\
\text { threshold level; red cell denotes breakthrough level; purple cell denotes SWIR bands currently used but additional bands } \\
\text { needed] }\end{array}$} & \multicolumn{10}{|c|}{ Spectral Bands } \\
\hline Mission Service Area (MSA) & $\begin{array}{l}\text { Supported Key Product or Service } \\
\text { (KPS) }\end{array}$ & Requirement & $\frac{\varrho}{\frac{D}{0}}$ & \begin{tabular}{|l}
$Ð$ \\
$\Phi$ \\
$\vdots$ \\
\end{tabular} & $\underset{\mathscr{x}}{\mathscr{x}}$ & $\frac{\cong}{z}$ & $\sum_{n}^{\cong}$ & $\stackrel{\cong}{\models}$ & $\begin{array}{l}z \\
\vdots \\
a\end{array}$ & 3 & $\frac{3}{\overline{0}}$ & 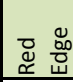 \\
\hline National crop forecasting & National crop forecast & Land surface temperature & & & & & & & & & & \\
\hline Water management and delivery & Consumptive use & Land surface temperature & & & & & & & & & & \\
\hline Water management and delivery & Riparian vegetation mapping & Land surface temperature & & & & & & & & & & \\
\hline $\begin{array}{l}\text { Climate and land use change / land } \\
\text { carbon research }\end{array}$ & Ecosystem carbon assessment & Land use classes & & & & & & & & & & \\
\hline Global crop forecasting & Crop area & Land use classes & & & & & & & & & & \\
\hline Global crop forecasting & Crop area & Land use classes & & & & & & & & & & \\
\hline $\begin{array}{l}\text { Climate and land use change / } \\
\text { ecosystem services }\end{array}$ & Global ecosystem mapping & Land use classes & & & & & & & & & & \\
\hline $\begin{array}{l}\text { Strategic habitat conservation / } \\
\text { inventory and monitoring }\end{array}$ & $\begin{array}{l}\text { Migratory birds and management } \\
\text { plans }\end{array}$ & Land use classes & & & & & & & & & & \\
\hline Water management and delivery & Consumptive use & Land use classes & & & & & & & & & & \\
\hline $\begin{array}{l}\text { Water science / hydrologic research } \\
\text { and development }\end{array}$ & National watershed monitoring & Land use classes & & & & & & & & & & \\
\hline National crop forecasting & Yield and water use estimates & Leaf Area Index (LAI) & & & & & & & & & & \\
\hline Mineral resources & Minerals assessment & Mineral type & & & & & & & & & & \\
\hline Mineral resources & Minerals assessment & Mineral type & & & & & & & & & & \\
\hline Mineral resources & Environmental impact assessment & Mineral type & & & & & & & & & & \\
\hline Mineral resources & Deposit modeling & Mineral type & & & & & & & & & & \\
\hline Soil and water conservation & Soil survey interpretation maps & Mineral type & & & & & & & & & & \\
\hline Compliance monitoring & Actuarial rate maps & $\begin{array}{l}\text { Nonphotosynthetic } \\
\text { vegetation }\end{array}$ & & & & & & & & & & \\
\hline Global crop forecasting & Crop yield & $\begin{array}{l}\text { Nonphotosynthetic } \\
\text { vegetation }\end{array}$ & & & & & & & & & & \\
\hline Soil and water conservation & Crop residue monitoring & $\begin{array}{l}\text { Nonphotosynthetic } \\
\text { vegetation }\end{array}$ & & & & & & & & & & \\
\hline Soil and water conservation & Crop residue monitoring & $\begin{array}{l}\text { Nonphotosynthetic } \\
\text { vegetation }\end{array}$ & & & & & & & & & & \\
\hline $\begin{array}{l}\text { Climate and land use change / land } \\
\text { carbon research }\end{array}$ & Ecosystem Carbon Assessment & Salinity & & & & & & & & & & \\
\hline
\end{tabular}


Preliminary Threshold and Breakthrough User Requirements Summary - Spectral Bands--Cont.

\begin{tabular}{|c|c|c|c|c|c|c|c|c|c|c|c|c|}
\hline \multicolumn{3}{|c|}{$\begin{array}{l}\text { [NIR, near infrared; SWIR, shortwave infrared; TIR, thermal infrared; PAN, panchromatic; UV, ultraviolet; blue cell denotes } \\
\text { threshold level; red cell denotes breakthrough level; purple cell denotes SWIR bands currently used but additional bands } \\
\text { needed] }\end{array}$} & \multicolumn{10}{|c|}{ Spectral Bands } \\
\hline Mission Service Area (MSA) & $\begin{array}{l}\text { Supported Key Product or Service } \\
\text { (KPS) }\end{array}$ & Requirement & $\frac{\varrho}{\frac{D}{D}}$ & ֻे & $\begin{array}{r}\mathscr{\mathscr { g }} \\
\stackrel{x}{ } \\
\end{array}$ & $\frac{\cong}{\bar{z}}$ & $\sum_{\sim}^{\cong}$ & $\stackrel{\cong}{上}$ & $\underset{⿺}{z}$ & 3 & $\frac{3}{\bar{\nu}}$ & 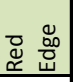 \\
\hline Compliance monitoring & $\begin{array}{l}\text { Compliance Monitoring } \\
\text { Investigations }\end{array}$ & Seasonally frozen ground & & & & & & & & & & \\
\hline $\begin{array}{l}\text { Climate and land use change / land } \\
\text { carbon research }\end{array}$ & Ecosystem carbon assessment & Soil classification & & & & & & & & & & \\
\hline $\begin{array}{l}\text { Conservation of forest biological } \\
\text { diversity }\end{array}$ & Digital soil mapping & Soil classification & & & & & & & & & & \\
\hline Soil and water conservation & Crop residue monitoring & Soil disturbance & & & & & & & & & & \\
\hline Compliance monitoring & $\begin{array}{l}\text { Compliance monitoring } \\
\text { investigations }\end{array}$ & Soil moisture / water content & & & & & & & & & & \\
\hline Global crop forecasting & Crop yield & Soil moisture / water content & & & & & & & & & & \\
\hline Land management & Local drought assessments & Soil moisture / water content & & & & & & & & & & \\
\hline Volcanoes & Volcano monitoring & Sulfur dioxide & & & & & & & & & & \\
\hline Volcanoes & Volcano assessment & Sulfur dioxide & & & & & & & & & & \\
\hline $\begin{array}{l}\text { Climate and land use change / land } \\
\text { change products }\end{array}$ & $\begin{array}{l}\text { Global Land Cover 30-meter } \\
\text { Dataset (GLC30m) }\end{array}$ & Surface reflectance & & & & & & & & & & \\
\hline National crop forecasting & Yield and water use estimates & Surface reflectance & & & & & & & & & & \\
\hline Global crop forecasting & Crop area & Surface water extent & & & & & & & & & & \\
\hline Volcanoes & Volcano research & Surface water extent & & & & & & & & & & \\
\hline $\begin{array}{l}\text { Strategic habitat conservation / } \\
\text { inventory and monitoring }\end{array}$ & $\begin{array}{l}\text { Migratory birds and management } \\
\text { plans }\end{array}$ & Surface water extent & & & & & & & & & & \\
\hline Compliance monitoring & Actuarial rate maps & Surface water extent & & & & & & & & & & \\
\hline Compliance monitoring & $\begin{array}{l}\text { Compliance monitoring } \\
\text { investigations }\end{array}$ & Surface water extent & & & & & & & & & & \\
\hline National crop forecasting & National crop forecast & Surface water extent & & & & & & & & & & \\
\hline $\begin{array}{l}\text { Strategic habitat conservation / } \\
\text { inventory and monitoring }\end{array}$ & $\begin{array}{l}\text { Landscape analysis and vegetation } \\
\text { monitoring }\end{array}$ & Surface water extent & & & & & & & & & & \\
\hline $\begin{array}{l}\text { Water science / hydrologic research } \\
\text { and development }\end{array}$ & National watershed monitoring & Surface water extent & & & & & & & & & & \\
\hline Soil and water conservation & Resource inventories & Surface water extent & & & & & & & & & & \\
\hline Intermediate products & LANDFIRE existing vegetation & $\begin{array}{l}\text { Top of atmosphere } \\
\text { reflectance }\end{array}$ & & & & & & & & & & \\
\hline
\end{tabular}


Preliminary Threshold and Breakthrough User Requirements Summary - Spectral Bands--Cont.

\begin{tabular}{|c|c|c|c|c|c|c|c|c|c|c|c|c|}
\hline \multicolumn{3}{|c|}{$\begin{array}{l}\text { [NIR, near infrared; SWIR, shortwave infrared; TIR, thermal infrared; PAN, panchromatic; UV, ultraviolet; blue cell denotes } \\
\text { threshold level; red cell denotes breakthrough level; purple cell denotes SWIR bands currently used but additional bands } \\
\text { needed] }\end{array}$} & \multicolumn{10}{|c|}{ Spectral Bands } \\
\hline Mission Service Area (MSA) & $\begin{array}{l}\text { Supported Key Product or Service } \\
\text { (KPS) }\end{array}$ & Requirement & $\frac{\varrho}{\omega}$ & ఖั & $\underset{\mathscr{\Perp}}{\mathscr{\Psi}}$ & $\frac{\Upsilon}{z}$ & $\sum_{\varpi}^{\cong}$ & $\stackrel{\cong}{\stackrel{\cong}{上}}$ & $\underset{a}{z}$ & 3 & $\frac{3}{\overline{0}}$ & 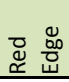 \\
\hline Intermediate products & National Landcover Dataset (NLCD) & $\begin{array}{l}\text { Top of atmosphere } \\
\text { reflectance }\end{array}$ & & & & & & & & & & \\
\hline $\begin{array}{l}\text { Assessment of forest affected by } \\
\text { abiotic agents }\end{array}$ & $\begin{array}{l}\text { Rapid Assessment of Vegetation } \\
\text { Condition after Wildfire (RAVG) }\end{array}$ & Tree cover canopy & & & & & & & & & & \\
\hline Global crop forecasting & Crop yield & Vegetation condition & & & & & & & & & & \\
\hline Global crop forecasting & Crop yield & Vegetation condition & & & & & & & & & & \\
\hline Global crop forecasting & Rapid response & Vegetation condition & & & & & & & & & & \\
\hline Land management & Local drought assessments & Vegetation condition & & & & & & & & & & \\
\hline National crop forecasting & National crop forecast & Vegetation condition & & & & & & & & & & \\
\hline $\begin{array}{l}\text { Climate and land use change / land } \\
\text { change products }\end{array}$ & National Drought Assessment & Vegetation condition & & & & & & & & & & \\
\hline $\begin{array}{l}\text { Climate and land use change / land } \\
\text { change products }\end{array}$ & Phenology assessment & Vegetation condition & & & & & & & & & & \\
\hline Compliance monitoring & Actuarial rate maps & Vegetation condition & & & & & & & & & & \\
\hline Compliance monitoring & Actuarial rate maps & Vegetation condition & & & & & & & & & & \\
\hline Compliance monitoring & $\begin{array}{l}\text { Compliance monitoring } \\
\text { investigations }\end{array}$ & Vegetation condition & & & & & & & & & & \\
\hline Compliance monitoring & $\begin{array}{l}\text { Determine condition of the } \\
\text { vegetation on the rangelands }\end{array}$ & Vegetation condition & & & & & & & & & & \\
\hline Water management and delivery & Consumptive use & Vegetation condition & & & & & & & & & & \\
\hline $\begin{array}{l}\text { Assessment of forest affected by } \\
\text { abiotic agents }\end{array}$ & $\begin{array}{l}\text { Rapid Assessment of Vegetation } \\
\text { Condition after Wildfire (RAVG) }\end{array}$ & Vegetation condition & & & & & & & & & & \\
\hline Land change products & Irrigation monitoring & Vegetation condition & & & & & & & & & & \\
\hline $\begin{array}{l}\text { Maintenance of ecosystem health } \\
\text { and safety }\end{array}$ & Forest disturbance assessment & Vegetation condition & & & & & & & & & & \\
\hline $\begin{array}{l}\text { Assessment of forest affected by } \\
\text { abiotic agents }\end{array}$ & $\begin{array}{l}\text { Monitoring Trends in Burn Severity } \\
\text { (MTBS) }\end{array}$ & Vegetation condition & & & & & & & & & & \\
\hline $\begin{array}{l}\text { Climate and land use change / land } \\
\text { change products }\end{array}$ & Irrigated land dynamics & Vegetation condition & & & & & & & & & & \\
\hline $\begin{array}{l}\text { Maintenance of ecosystem health } \\
\text { and safety }\end{array}$ & Forest disturbance queuing & Vegetation condition & & & & & & & & & & \\
\hline $\begin{array}{l}\text { Maintenance of ecosystem health } \\
\text { and safety }\end{array}$ & Forest disturbance assessment & Vegetation condition & & & & & & & & & & \\
\hline $\begin{array}{l}\text { Climate and land use change / land } \\
\text { change products }\end{array}$ & $\begin{array}{l}\text { Global Land Cover 30-meter } \\
\text { Dataset (GLC30m) }\end{array}$ & Vegetation cover & & & & & & & & & & \\
\hline Compliance monitoring & $\begin{array}{l}\text { Compliance monitoring } \\
\text { investigations }\end{array}$ & Vegetation cover & & & & & & & & & & \\
\hline
\end{tabular}


Preliminary Threshold and Breakthrough User Requirements Summary - Spectral Bands--Cont.

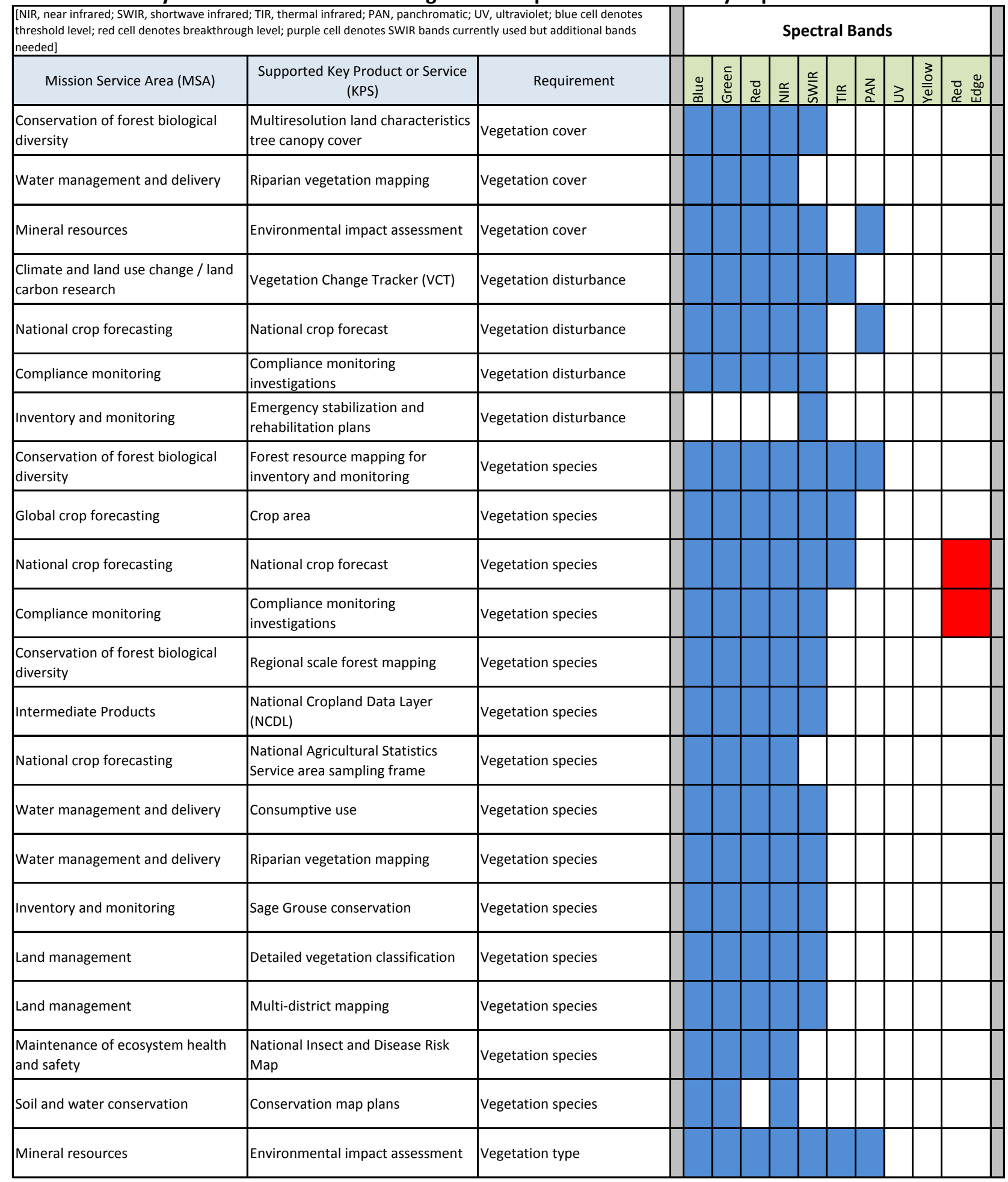


Preliminary Threshold and Breakthrough User Requirements Summary - Spectral Bands--Cont.

\begin{tabular}{|c|c|c|c|c|c|c|c|c|c|c|c|c|}
\hline \multicolumn{3}{|c|}{$\begin{array}{l}\text { [NIR, near infrared; SWIR, shortwave infrared; TIR, thermal infrared; PAN, panchromatic; UV, ultraviolet; blue cell denotes } \\
\text { threshold level; red cell denotes breakthrough level; purple cell denotes SWIR bands currently used but additional bands } \\
\text { needed] }\end{array}$} & \multicolumn{10}{|c|}{ Spectral Bands } \\
\hline Mission Service Area (MSA) & $\begin{array}{l}\text { Supported Key Product or Service } \\
\text { (KPS) }\end{array}$ & Requirement & $\frac{g}{\frac{y}{m}}$ & ญे & $\begin{array}{l}\text { ర্் } \\
\check{x}\end{array}$ & $\stackrel{\cong}{\Sigma}$ & $\sum_{n}^{\infty}$ & $\stackrel{\cong}{\models}$ & $\underset{a}{a}$ & 3 & $\frac{3}{\overline{0}}$ & ஜ \\
\hline Volcanoes & Hazards communication & Volcanic activity & & & & & & & & & & \\
\hline Volcanoes & Volcano monitoring & Volcanic deposits & & & & & & & & & & \\
\hline $\begin{array}{l}\text { Strategic habitat conservation / } \\
\text { inventory and monitoring }\end{array}$ & $\begin{array}{l}\text { Landscape analysis and vegetation } \\
\text { monitoring }\end{array}$ & Wetland classification & & & & & & & & & & \\
\hline Global crop forecasting & Rapid response & Wildfires & & & & & & & & & & \\
\hline
\end{tabular}

National Land Imaging Requirements Pilot Project

Preliminary Target User Requirements Summary - Resolution and Revisit

\begin{tabular}{|c|c|c|c|c|c|c|c|c|c|c|c|c|c|}
\hline \multicolumn{3}{|c|}{ [Green denotes target requirement] } & \multicolumn{7}{|c|}{ Resolution } & \multicolumn{4}{|c|}{ Revisit } \\
\hline Mission Service Area (MSA) & $\begin{array}{l}\text { Supported Key Product or Service } \\
\text { (KPS) }\end{array}$ & Requirement & 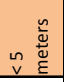 & 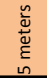 & 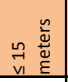 & 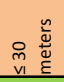 & 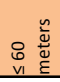 & 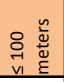 & 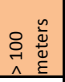 & $\begin{array}{l}n \\
\frac{n}{\pi} \\
N \\
v \\
v\end{array}$ & $\begin{array}{l}\stackrel{n}{\pi} \\
\frac{\pi}{0} \\
\dot{\sigma} \\
v_{1} \\
\end{array}$ & $\begin{array}{l}n \\
\text { i⿱ } \\
\text { on } \\
\text { vi } \\
\text { vi }\end{array}$ & $\begin{array}{l}l_{1} \\
\vec{a} \\
v_{1} \\
\frac{\pi}{0}\end{array}$ \\
\hline Mineral resources & Minerals assessment & Mineral type & & & & & & & & & & & \\
\hline Mineral resources & Deposit modeling & Mineral type & & & & & & & & & & & \\
\hline National crop forecasting & National crop forecast & Vegetation species & & & & & & & & & & & \\
\hline $\begin{array}{l}\text { Water management and } \\
\text { delivery }\end{array}$ & Riparian vegetation mapping & Vegetation species & & & & & & & & & & & \\
\hline $\begin{array}{l}\text { Water management and } \\
\text { delivery }\end{array}$ & Riparian vegetation mapping & Vegetation species & & & & & & & & & & & \\
\hline National crop forecasting & Yield and water use estimates & Land surface temperature & & & & & & & & & & & \\
\hline $\begin{array}{l}\text { Climate and land use change / } \\
\text { ecosystem services }\end{array}$ & Global ecosystem mapping & Land use classes & & & & & & & & & & & \\
\hline $\begin{array}{l}\text { Conservation of forest } \\
\text { biological diversity }\end{array}$ & Regional scale forest mapping & Vegetation species & & & & & & & & & & & \\
\hline $\begin{array}{l}\text { Water science / hydrologic } \\
\text { research and development }\end{array}$ & National watershed monitoring & Land use classes & & & & & & & & & & & \\
\hline $\begin{array}{l}\text { Maintenance of ecosystem } \\
\text { health and safety }\end{array}$ & Forest disturbance assessment & Vegetation condition & & & & & & & & & & & \\
\hline $\begin{array}{l}\text { Maintenance of ecosystem } \\
\text { health and safety }\end{array}$ & Effectiveness of mitigation & Vegetation condition & & & & & & & & & & & \\
\hline Land change products & Irrigation monitoring & Vegetation condition & & & & & & & & & & & \\
\hline Volcanoes & Volcano monitoring & Volcanic deposits & & & & & & & & & & & \\
\hline Volcanoes & Volcano monitoring & Land surface elements & & & & & & & & & & & \\
\hline
\end{tabular}


National Land Imaging Requirements Pilot Project

Preliminary Target User Requirements Summary - Spectral Bands

\begin{tabular}{|c|c|c|c|c|c|c|c|c|c|c|c|c|}
\hline \multicolumn{3}{|c|}{ [Green denotes target requirement] } & \multicolumn{10}{|c|}{ Spectral Bands } \\
\hline Mission Service Area (MSA) & $\begin{array}{l}\text { Supported Key Product or Service } \\
\text { (KPS) }\end{array}$ & Requirement & $\frac{\varrho}{\frac{\partial}{\omega}}$ & 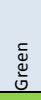 & $\begin{array}{l}\underset{\mathscr{g}}{0} \\
\end{array}$ & 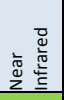 & 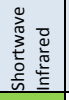 & 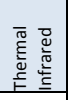 & 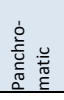 & $\begin{array}{l}\frac{0}{0} \\
\frac{0}{20} \\
\frac{0}{5} \\
\frac{5}{5} \\
\end{array}$ & $\frac{3}{\frac{3}{\omega}}$ & 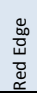 \\
\hline Mineral resources & Minerals assessment & Mineral type & & & & & & & & & & \\
\hline Mineral resources & Deposit modeling & Mineral type & & & & & & & & & & \\
\hline National crop forecasting & National crop forecast & Vegetation species & & & & & & & & & & \\
\hline Water management and delivery & Riparian vegetation mapping & Vegetation species & & & & & & & & & & \\
\hline Water management and delivery & Riparian vegetation mapping & Vegetation species & & & & & & & & & & \\
\hline National crop forecasting & Yield and water use estimates & Land surface temperature & & & & & & & & & & \\
\hline National crop forecasting & Yield and water use estimates & Surface reflectance & & & & & & & & & & \\
\hline $\begin{array}{l}\text { Climate and land use change / ecosystem } \\
\text { services }\end{array}$ & Global ecosystem mapping & Land use classes & & & & & & & & & & \\
\hline Conservation of forest biological diversity & Regional scale forest mapping & Vegetation species & & & & & & & & & & \\
\hline $\begin{array}{l}\text { Water science / hydrologic research and } \\
\text { development }\end{array}$ & National watershed monitoring & Land use classes & & & & & & & & & & \\
\hline Maintenance of ecosystem health and safety & Forest disturbance assessment & Vegetation condition & & & & & & & & & & \\
\hline Maintenance of ecosystem health and safety & Effectiveness of mitigation & Vegetation condition & & & & & & & & & & \\
\hline Land change products & Irrigation monitoring & Vegetation condition & & & & & & & & & & \\
\hline Volcanoes & Volcano monitoring & Volcanic deposits & & & & & & & & & & \\
\hline Volcanoes & Volcano monitoring & Land surface elements & & & & & & & & & & \\
\hline
\end{tabular}

